\title{
Mesenchymal stem cell-based therapy and exosomes in COVID-19: current trends and prospects
}

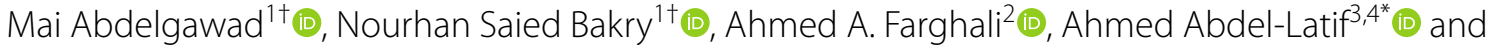 \\ Ahmed Lotfy ${ }^{1 *}$ (D)
}

\begin{abstract}
Novel coronavirus disease 2019 (COVID-19) is caused by severe acute respiratory syndrome coronavirus-2. The virus causes an exaggerated immune response, resulting in a cytokine storm and acute respiratory distress syndrome, the leading cause of COVID-19-related mortality and morbidity. So far, no therapies have succeeded in circumventing the exacerbated immune response or cytokine storm associated with COVID-19. Mesenchymal stem cells (MSCs), through their immunomodulatory and regenerative activities, mostly mediated by their paracrine effect and extracellular vesicle production, have therapeutic potential in many autoimmune, inflammatory, and degenerative diseases. In this paper, we review clinical studies on the use of MSCs for COVID-19 treatment, including the salutary effects of MSCs on the pathophysiology of COVID-19 and the immunomodulation of the cytokine storm. Ongoing clinical trial designs, cell sources, dose and administration, and populations are summarized, and the paracrine mode of benefit is discussed. We also offer suggestions for optimizing MSC-based therapies, including genetic engineering, strategies for cell surface modification, nanotechnology applications, and combination therapies.
\end{abstract}

Keywords: Mesenchymal stem cell, Mesenchymal stromal cell, Exosomes, COVID-19, Immunomodulation, Cytokine storm, SARS-CoV-2

\section{Background}

The coronavirus disease 2019 (COVID-19) outbreak emerged in December 2019 in Wuhan, China, but quickly spread worldwide, and the number of cases increased exponentially, with devastating effects on the global economy and public health. The World Health Organization (WHO) designated COVID-19 as a public

\footnotetext{
*Correspondence: abdel-latif@uky.edu; ahmed.lotfy@psas.bsu.edu.eg; lotfy_bio@hotmail.com

${ }^{\dagger}$ Mai Abdelgawad and Nourhan Saied Bakry have contributed equally to this work

1 Biotechnology and Life Sciences Department, Faculty of Postgraduate Studies for Advanced Sciences (PSAS), Beni-Suef University, Beni Suef 62511, Egypt

${ }^{3}$ Gill Heart Institute and Division of Cardiovascular Medicine, University of Kentucky and the Lexington VA Medical Center, Lexington, KY, USA Full list of author information is available at the end of the article
}

health crisis because of its high morbidity and mortality (covid19.who.int). According to the Centers for Disease Control and Prevention [1], COVID-19 is characterized by high fever, fatigue, loss of taste and smell, respiratory symptoms, decreased oxygen saturation, and shortness of breath. The causative organism, severe acute respiratory syndrome corona virus-2 (SARS-CoV-2), can also cause neurological disorders, such as encephalopathy, encephalitis, anosmia, ageusia, and Guillain-Barré syndrome, and has been found in the cerebrospinal fluid [2]. COVID-19 can also affect the cardiovascular system, with direct effects on the myocardium and associated myocarditis that causes acute coronary syndrome and myocardial infraction [3]. Some patients suffer from venous thromboembolism and coagulopathy, and these patients in the intensive care unit (ICU) are typically

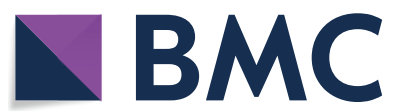

(c) The Author(s) 2021. Open Access This article is licensed under a Creative Commons Attribution 4.0 International License, which permits use, sharing, adaptation, distribution and reproduction in any medium or format, as long as you give appropriate credit to the original author(s) and the source, provide a link to the Creative Commons licence, and indicate if changes were made. The images or other third party material in this article are included in the article's Creative Commons licence, unless indicated otherwise in a credit line to the material. If material is not included in the article's Creative Commons licence and your intended use is not permitted by statutory regulation or exceeds the permitted use, you will need to obtain permission directly from the copyright holder. To view a copy of this licence, visit http://creativecommons.org/licenses/by/4.0/. The Creative Commons Public Domain Dedication waiver (http://creativeco mmons.org/publicdomain/zero/1.0/) applies to the data made available in this article, unless otherwise stated in a credit line to the data. 
treated with anticoagulation therapy [4-6]. COVID-19 is characterized by cytokine storms, and patients are positive for cytokines, such as monocyte chemoattractant protein 1 (MCP1), macrophage inflammatory protein (MIP) $1 \alpha$, interleukin (IL)-6, IL-2, IL-7, IL-10, and tumor necrosis factor alpha (TNF- $\alpha)[7,8]$.

There are no approved and effective therapeutics against COVID-19, and scientists are grappling with time to find effective treatments and vaccines. Cell-induced therapies using stem cells, particularly mesenchymal stem cells (MSCs), have been a primary target of therapeutic studies. Many drugs have been repurposed to accelerate drug development $[9,10]$, while mass vaccination campaigns are being slowly rolled out [11]. Interestingly, the patient response to treatment and therapeutic efficacy has been heterogeneous.

MSCs are self-renewing multipotent stem cells that can differentiate into several cell types. They represent a promising therapy for several chronic lung diseases with high fatality and morbidity rates, such as chronic obstructive pulmonary disease (COPD), obstructive bronchiolitis, idiopathic pulmonary fibrosis, and acute respiratory distress syndrome (ARDS).

Here, we review the use of MSCs as a potential therapy for COVID-19, summarizing their role and immunomodulatory effect in response to a cytokine storm. We discuss completed and ongoing clinical trials and the debate over the use of acellular MSC-based products, such as exosomes, and their effect on COVID-19 pathophysiology. Finally, to improve the chances of treatment success, we suggest methods of enhancing the therapeutic efficacy of MSCs, such as combination therapies, genetic modification and engineering, nanotechnology and nanomaterials, and MSC surface modifications.

\section{SARS-CoV-2 infection}

The novel SARS-CoV-2 [12] shares $79.6 \%$ genetic similarity with other human coronaviruses and uses the same target receptor, angiotensin-converting enzyme 2 (ACE 2), for host cell entry [13]. ACE2 is ubiquitously expressed, with high levels in the kidneys, esophagus, colon, small intestine, heart, and lungs $[13,14]$. SARS$\mathrm{CoV}-2$ pathophysiology and virulence are linked to its structural and nonstructural proteins. SARS-CoV-2 can enter type II alveolar cells or other ACE2-expressing cells via the spike (S) protein [15]. Following virus-host cell membrane fusion, viral RNA is released into the host cell, where viral replication, transcription, and translation occur, followed by the assembly of viral proteins and messenger RNAs (mRNAs) into new virions, which are then liberated $[12,16]$. Upon SARS-CoV-2 infection, the secreted chemokines induce inflammation of the alveolar and capillary epithelia, causing alveolar and interstitial edema, eventually impairing pulmonary function. Pro-inflammatory granulocytes, monocytes, and macrophages are produced, with reduction in regulatory and anti-inflammatory immune cells. These findings are consistent with histological examinations of lung biopsies that show signs of ARDS, in addition to liver, kidney, and heart damage [13-17].

\section{COVID-19 and cytokine storms}

COVID-19 ARDS is characterized by air exchange dysfunction, edematous changes, secondary infections, and a cytokine storm that can cause multiple-organ dysfunction [13]. There is an increase in leukocytes and inflammatory cytokines and chemokines, such as granulocyte colony-stimulating factor (G-CSF), granulocyte-macrophage colony-stimulating factor (GM-CSF), IL-1 $\beta$, IL-1 receptor type 1 (IL-1RA), Il-7, IL-8, IL-9, IL-10, fibroblast growth factor 2 (FGF-2), MCP1, vascular endothelial growth factor A (VEGF-A), MIP1- $\alpha$ and MIP1- $\beta$, interferon gamma (IFNY), IFN $\gamma$-induced protein 10 (IP10), platelet-derived growth factor B (PDGFB), and TNF- $\alpha$ [18]. Many drugs have been repurposed for COVID19 treatment but with limited success. As the cytokine storm is the leading cause of death due to COVID-19, immunotherapy seems a favorable treatment option [8]. Tocilizumab (Actemra) is an immunotherapeutic that inhibits IL-6, which plays an integral role in the cytokine storm. However, there is a desperate need for a treatment that can act on a broad range of cytokines [19], and stem cell therapy may be a more beneficial therapeutic approach to treating COVID-19.

\section{MSCs}

In 1966, Friedenstein et al. discovered that fibroblastoids, obtained from murine bone marrow (BM), differentiate into osteocytes when subcutaneously transplanted. Fibroblastoids have since been named MSCs and have regenerative, multilineage differentiation, self-renewal, and immunomodulatory properties in vitro and in vivo, where they form a reservoir of restorative cells. MSCs can migrate to any part of the body, including wound, disease, and inflamed sites, where they modulate an immune response or differentiate into specific cell types [20-24]. MSCs can activate a tissue's inhabitant stem cells to participate in the healing process [25].

Significant advances have been made in MSC isolation, culture, characterization, and differentiation for exogenous use, due to their low immunogenic profile. MSCs can be isolated from peripheral blood, the umbilical cord, adipose (AD) tissue, and BM [26-29]. They express CD90, CD73, and CD105 but not CD45, CD34, CD14, $\mathrm{CD} 11 \mathrm{~b}, \mathrm{CD} 79 \alpha$, and human leukocyte antigen (HLA)-DR [30]. Under specific conditions, MSCs can be expanded 
in vitro and induced to differentiate into diverse cell types, such as osteoblasts, chondroblasts, ligamentous tissue, neuronal cells, stromal cells, and adipocytes [31].

MSCs have been applied in numerous preclinical and clinical studies [21,22] to determine their safety and potential for mitigating inflammatory, degenerative, and autoimmune diseases, such as epilepsy, osteoarthritis, multiple sclerosis, rheumatoid arthritis, Crohn's disease, inflammatory bowel disease (IBD), systemic lupus erythematosus, type 1 diabetes (T1D), autoimmune hepatitis, amyotrophic lateral sclerosis, and corneal epithelial stem cell deficiency [32-44].

\section{Immunomodulation}

MSCs are considered the only stem cell type with immunomodulatory activity and are, therefore, a primary target for therapeutic development for autoimmune disease and inflammation [44]. MSCs secrete immunomodulators, including chemokines, IL-6 and prostaglandin E2 (PGE2), hemoxygenase-1, leukocyte inhibitory factor, indolamine 2,3-dioxygenase (IDO), and transforming growth factor $\beta$ [45]. MSCs also induce IL-10 expression [46]. Human umbilical cord tissue-derived MSCs (hUCMSCs) reprogram macrophages and monocytes via cytoplasmic organelles (RNA processing bodies [p-bodies]), a critical lung inflammatory inhibitor. These p-bodies are engulfed by macrophages and monocytes, modulating transcription and inhibiting $\mathrm{T}$ cell activation. Lowdensity lipoprotein receptor-related proteins mediate this interaction on the surface of macrophages and monocytes while blocking pharmacological inhibitors. These findings provide new insight into the inflammatory modulation of MSCs without long-term engulfment by indirectly inhibiting the $\mathrm{T}$ cell response through monocyte and macrophage reprogramming by p-bodies [46].

MSCs can migrate to injured and affected tissue. In lung injury, ARDS, and sepsis, MSCs migrate to and are trapped in the lungs, promoting secretion of antimicrobial agents, cytokines, and growth factors [47].

\section{MSCs and ARDS}

Many preclinical and clinical studies have illustrated the therapeutic potential of MSCs in ARDS [48-53]. In a bleomycin-induced lung injury murine model, lung cells were protected from injury and fibrosis by migration of transplanted MSCs to the injury site, where they differentiated into lung cells and inhibited inflammatory cytokine production [48]. In a phase 1 clinical study, the safety of intravenous (IV) infusion of BM-MSCs in moderate-to-severe ARDS patients was validated; however, further studies are required for therapeutic efficacy [52]. MSCs mitigate the cytokine storm via IL-10 and IL-1RA induction and TNF- $\alpha$ and neutrophil influx and assembly inhibition [50, 54]. MSC-secreted keratinocyte growth factor (KGF) induces alveolar epithelial cell repair and proliferation via IL-1RA, GM-CSF, and matrix metalloproteinase-9 (MMP-9) induction [54-56]. VEGF and hepatocyte growth factor (HGF) secreted by MSCs reduce endothelial cell permeation $[55,56]$. These findings suggest the potential utility of MSCs as treatment for COVID-19 ARDS patients. The potential beneficial effects are summarized in Fig. 1.

\section{Studies on MSC therapy for COVID-19}

Multiple studies have used MSCs in the COVID-19 setting (Table 1 and Additional file 1). Their therapeutic utility varies by stage of disease:

- Mild: mild clinical manifestations

- Moderate or common: fever, respiratory symptoms, pneumonia on X-ray or computed tomography (CT)

- Severe: respiratory distress (respiratory rate $[R R] \geq 30 / \mathrm{min}$ ), oxygen saturation $\leq 93 \%$ at rest, or arterial partial pressure of oxygen $\left(\mathrm{PaO}_{2}\right)$ /fraction of $\mathrm{O}_{2}$ inspiration $\left(\mathrm{FiO}_{2}\right) \leq 300 \mathrm{mmHg}$

- Critically ill: respiratory failure needing mechanical ventilation, shock, shock with other organ failure, or needing ICU monitoring and treatment

One case report described a severely ill patient with COVID-19 who suffered clinical deterioration and was put on a non-invasive mechanical ventilator despite standard therapy. After three doses of $5 \times 10^{7}$ hUC-MSCs on 3 separate days, the patient's symptoms and laboratory values improved. The patient was weaned off the ventilator 1 day after the second MSC dose. Lymphopenia, including CD3, CD4, and CD8 $\mathrm{T}$ cell counts, resolved, with neutrophilia alleviation, and C-reactive protein (CRP), aspartate transaminase (AST), alanine transaminase (ALT), d-dimer, and bilirubin levels decreased [57].

A clinical pilot study of 10 COVID-19 patients (7 in the treatment group and 3 in the control group) evaluated the therapeutic efficacy of IV MSC administration. In the treatment group, one patient was critically ill, four had severe symptoms, and two were moderate cases. After 2-4 days of $10^{6} \mathrm{MSCs} / \mathrm{kg}$ administration, all symptoms (fever, fatigue, hypoxia, dyspnea) resolved. CRP levels decreased, oxygen saturation and lymphocytes increased, and cell types that mediate the cytokine storm $\left(\mathrm{CXCR}^{+}{ }^{+} \mathrm{CD} 4^{+} \mathrm{T}\right.$ cells, $\mathrm{CXCR} 3^{+} \mathrm{CD} 8^{+} \mathrm{T}$ cells, and $\mathrm{CXCR3}^{+}$natural killer [NK] cells) markedly decreased in the critically ill patient. Regulatory $\mathrm{T}$ cells and dendritic cells increased in the critically ill and severely ill patients. No early or delayed adverse events (AEs) were detected. There was a significant drop in pro-inflammatory TNF- $\alpha$ and a significant build-up in IL-10 in the severely ill 


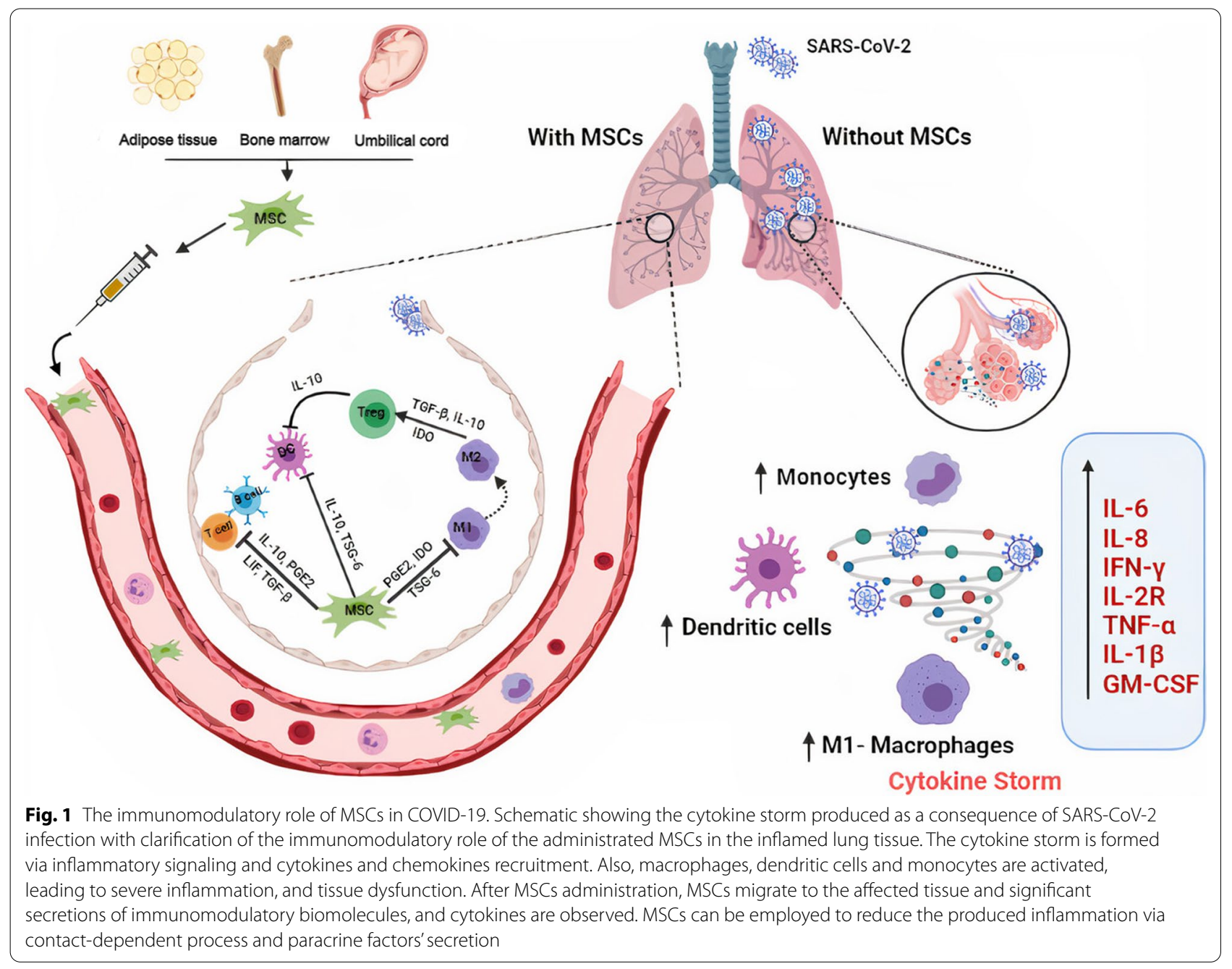

patients compared with the control group. The proposed mechanism of action was the overexpression of trophic anti-inflammatory factors transforming growth factor beta (TGF- $\beta$ ), HGF, LIF, GAL, NOA1, FGF, VEGF, EGF, BDNF, and NGF. Observed overexpression of SPC and SPA may indicate MSC differentiation to alveolar type II cells [58]. This study suggested the safety and potential efficacy of MSCs as COVID-19 treatment. However, the results were primarily based on the single critically ill patient, so further clinical studies are needed for validation.

In a study on the safety and efficacy of hUC-MSCs as severe COVID-19 treatment, patients were divided into two groups: control (standard treatment; $n=29$ ) and treatment (standard treatment + single IV dose of $2 \times 10^{6}$ hUC-MSCs $/ \mathrm{kg} ; n=12$ ). The treatment group manifested neither progression from severe to critical disease nor 28-day mortality, whereas four patients in the control group progressed to critical disease and 10.34\% of the patients died within 28 days. The treatment group exhibited more rapid improvement in clinical symptoms of dyspnea, weakness, and hypoxemia compared with the control group but only in patients $<65$ years old. Laboratory values of CRP, oxygen saturation, IL-6, and lymphocytes (significant between-group differences were detected) and CT further substantiated the therapeutic efficacy of MSCs, and clinical improvement in the treatment group was significant by day 7 [59]. No AEs were reported in the treatment group [59]. However, there were between-group differences in demographics and patient characteristics. In addition, the relatively small sample size might have limited the generalizability of results. Although the time to clinical improvement in the treatment group was significant, the 28-day mortality rate did not differ significantly.

Another study explored the safety and efficacy of hUCMSCs for moderate and severe COVID-19 treatment in 18 patients: control (standard treatment; $n=1$ ) and treatment (standard treatment $+3 \times 10^{7}$ hUC-MSCs/infusion on days 0,3 , and $6 ; n=9$ ) groups. In the treatment group, 


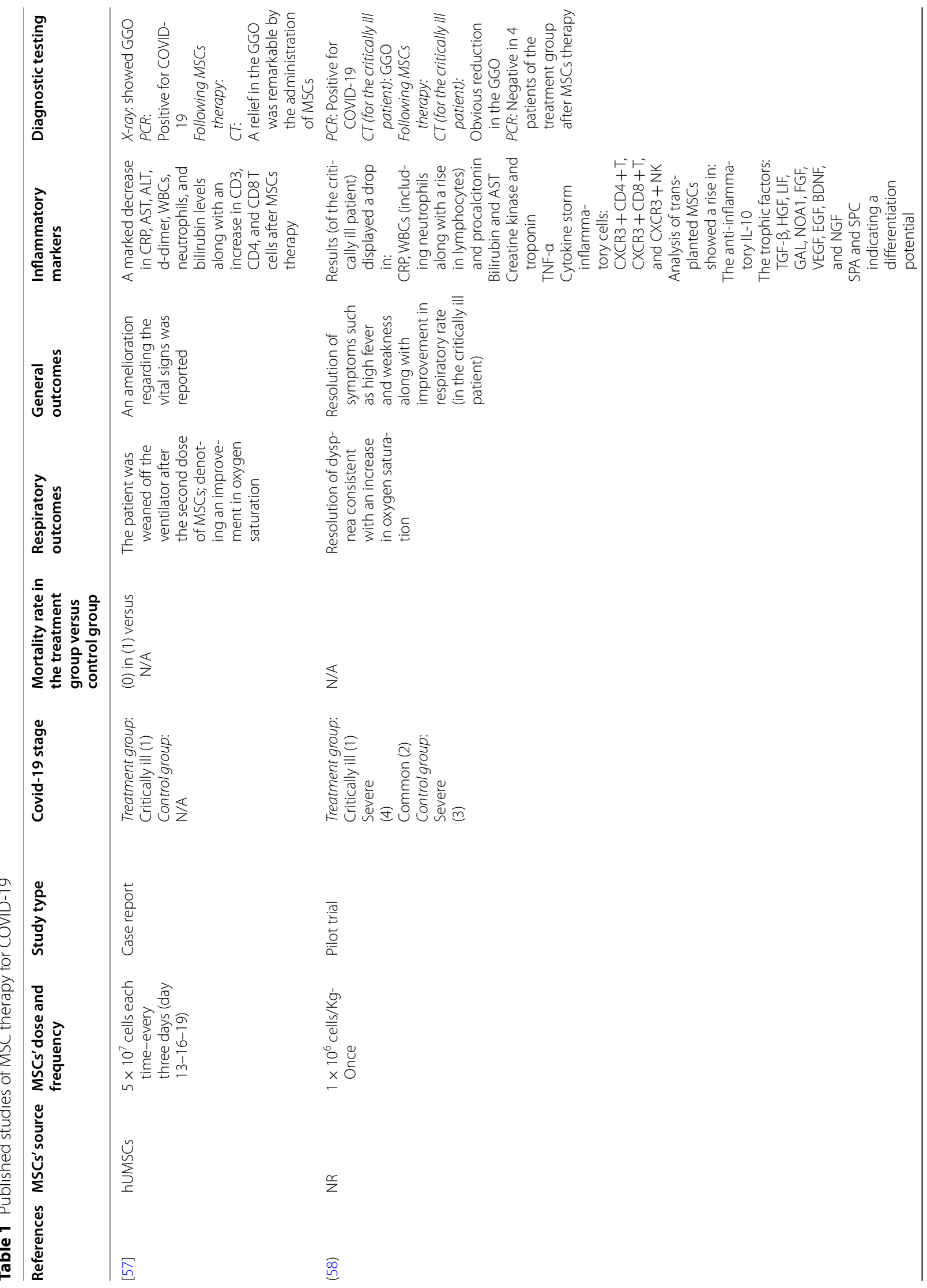




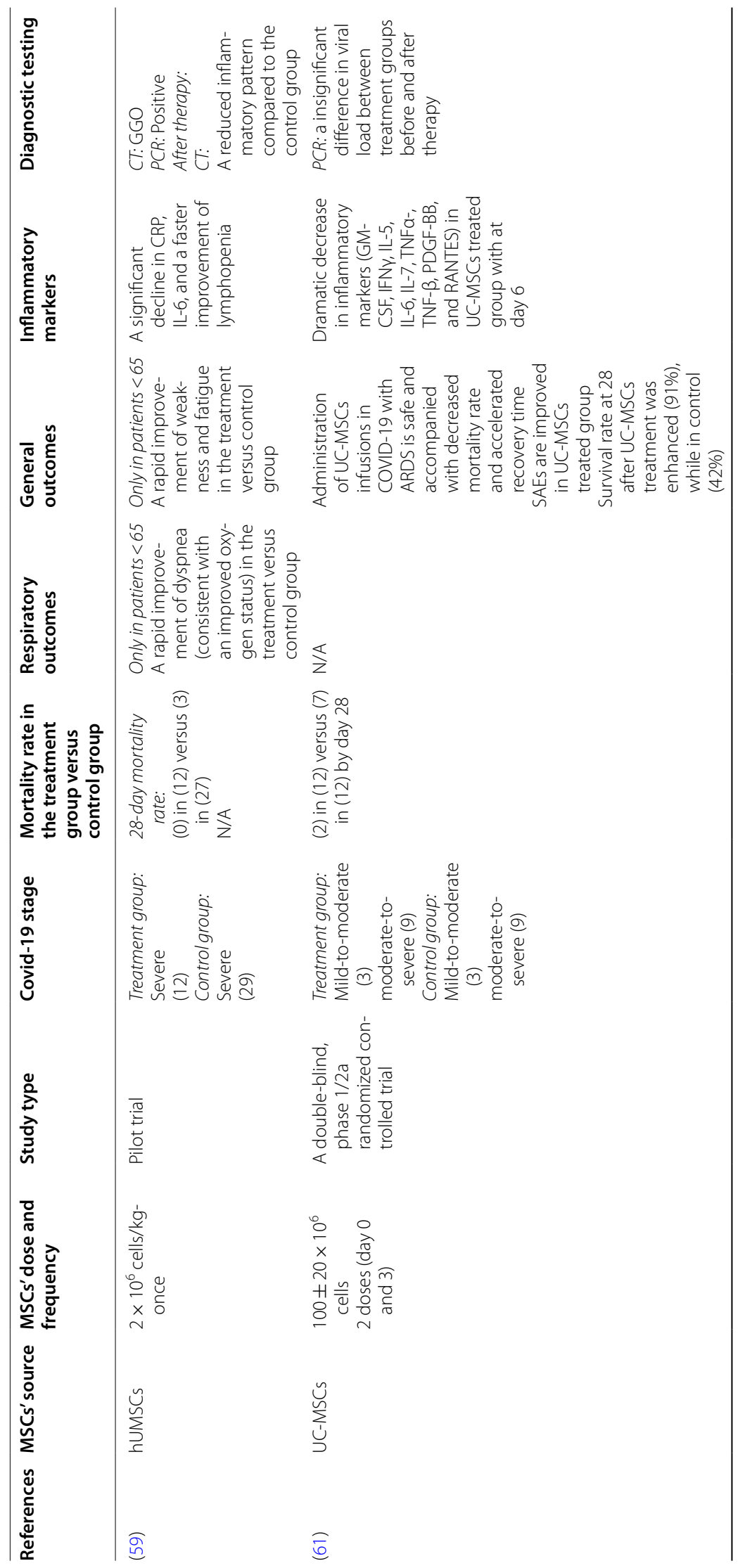




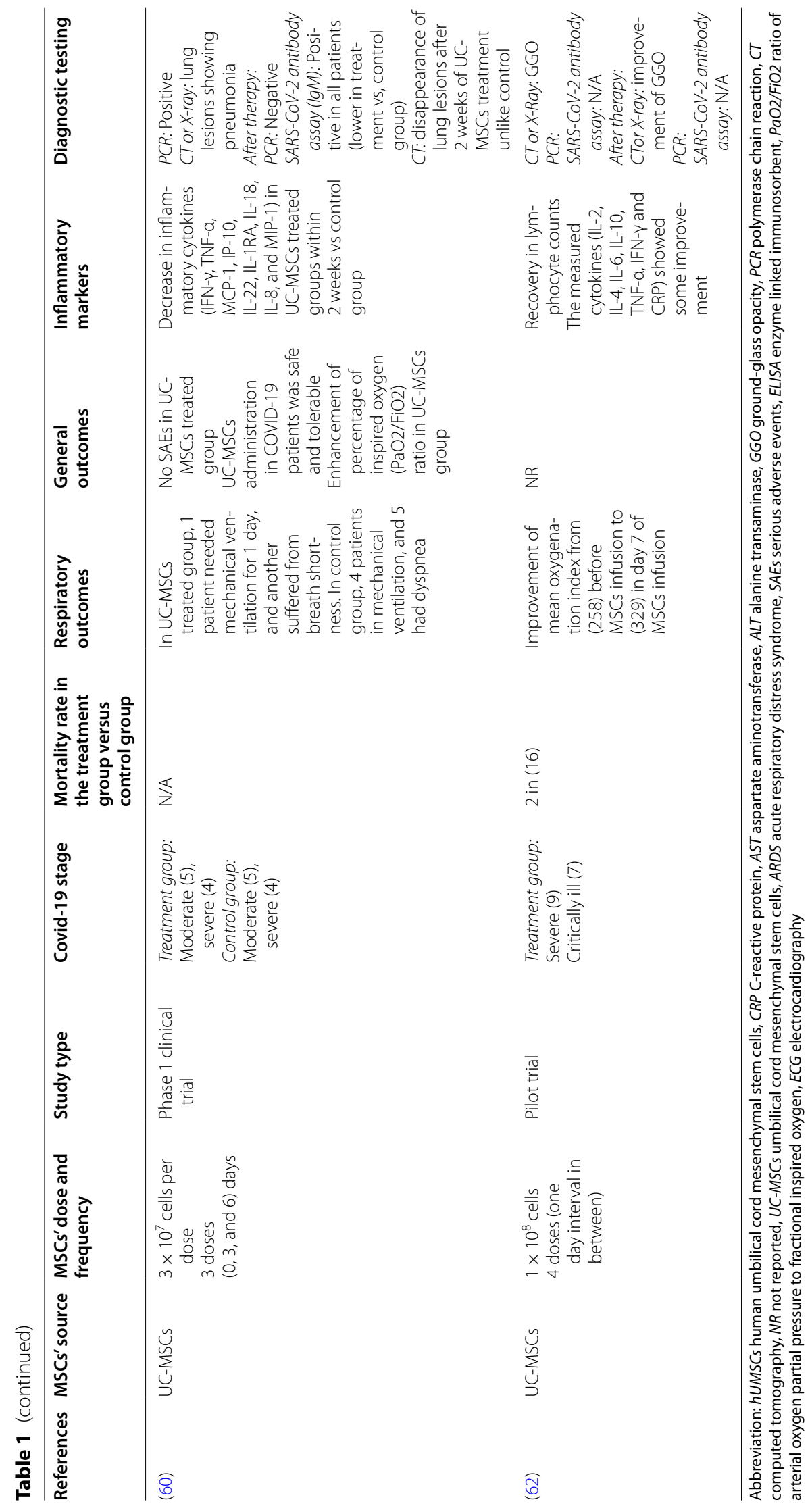


mild infusion-related AEs, including fever and flushing, were observed in two patients and transient hypoxia in one patient. Mechanical ventilation was needed in one patient in the treatment group versus four patients in the control group; however, the difference was not significant. No mortality rate was recorded, but inflammatory cytokines reduced. These results prove that IV infusion of MSCs may be safe for moderate and severe COVID19 treatment [60]. Interestingly, patients with higher IL-6 levels benefited more from hUC-MSC infusion, indicating that a more severe inflammatory environment triggers the MSC immunomodulatory response [60]. MSC activity was believed to occur by reducing inflammatory cytokines; however, a between-group comparison of their levels would have significantly affected the results.

Lanzoni et al. investigated the safety and therapeutic efficacy of hUC-MSCs in 24 COVID-19 patients (12 patients each in the control and treatment groups). In each group, three patients displayed mild-to-moderate ARDS, and nine displayed moderate-to-severe ARDS. In the treatment group, patients were given two IV infusions of $100 \pm 20 \times 10^{6} \mathrm{hUC}-\mathrm{MSCs}$ at days 0 and 3 plus standard treatment. No treatment-related AEs in terms of infusion-related reactions within the first $6 \mathrm{~h}$, cardiac arrest or death within $24 \mathrm{~h}$, or any other AEs were documented. There was a significant reduction in patient mortality, event-free survival, and time to recovery in the treatment group compared with the control group. A significant drop in the level of inflammatory cytokines and growth factors between days 0 and 6 further confirmed and justified the results. Therefore, hUC-MSCs are safe and effective in COVID-19 treatment [61].

A pilot, single-arm trial in 16 patients with severe and critically severe COVID-19 was performed. After four rounds of hUC-MSC transplantation, patients showed increased oxygen saturation, no allergic reactions, and cytokine storm improvement, demonstrating the safety and feasibility of hUC-MSCs in severe COVID-19 treatment [62].

In summary, monitoring of COVID-19 severity and recovery after MSC administration (Table 1) indicated that MSCs can ameliorate COVID-19 severity and patients can be weaned off the ventilator.

\section{Ongoing clinical trials of MSC therapy for COVID-19}

There are more than 55 ongoing clinical trials to assess the therapeutic efficacy and safety of MSCs in COVID19 (clinicaltrial.gov; Table 2 and Additional file 2) [63]. The majority of the trials are between phases 1 and 2, and few are in phase 3 [63]. The primary focus is severe COVID-19 because of high mortality and the emergence of promising treatments to decrease disease severity and mortality rates; moderate stage cases are also under study [63]. Most include male and female patients aged 18 years and older, primarily between 50 and 80 years old, while some include children and teenagers as well, and a few are limited to a specific age range [63]. Some of the trials have a low sample size (5-10 patients), while others have low-to-moderate (16-50 patients) or moderate (50-100 patients) sample sizes, which may not reflect the true impact of MSC therapy. However, trials using a large sample size (100-400 patients) may clearly reflect the effect of MSC therapy [63].

The MSC dose $\left(3-25 \times 10^{6}\right.$ cells $\left./ \mathrm{kg}\right)$ varies widely. More than 14 trials have injected 1 million cells $/ \mathrm{kg}$, while others have injected $0.5-3,25-90$, or $100-400$ million cells $/ \mathrm{kg}$ [63]. The number of administrated doses varies between one and five; the majority of trials have administered one to three doses: 13 trials, a single dose; 14 trials, two doses; 11 trials, three doses; 6 trials, four doses; and 3 trials, five doses [63].

The administration route in most trials is IV to minimize invasiveness, while optimizing cell retention and observable migration to the affected area [64]. A few trials have used intramuscular (IM) administration, while others have used inhalation and jet nebulization. MSCs have been sourced from the BM, umbilical cord, AD tissue, dental pulp, and pooled olfactory mucosa [63]. Many trials have used hUC-MSCs, particularly from Wharton's jelly (WJ-MSCs) [63]; the most common MSC sources in descending order are the umbilical cord, $\mathrm{BM}$, and $\mathrm{AD}$ tissue [63]. The vast majority of the MSCs used are allogeneic, while few are from autologous sources [63]. It is unclear which source is superior in COVID patients. The autologous source has the benefits of source availability and the absence of immune rejection and ethical controversy, although it is difficult to obtain a large number of cells, it is not helpful in emergencies, and it needs a biopsy, which exposes patients to risk. In contrast, the allogeneic source has the benefits of high cell availability, high-consistency materials, high patient throughput, no need for biopsy, and commercial availability [65]. A meta-analysis by McIntyre et al. suggests that the allogeneic source provides desirable outcomes compared with other cell sources (autologous, xenogeneic, or syngeneic). Therefore, allogeneic MSC sources might be promising in COVID-19 [66]. hUC-MSCs express the least major histocompatibility complex (MHC)-I, so using them as an allogeneic source does not cause an immune response [64, 67-69]. The umbilical cord is extremely rich in MSCs [68], is easily obtained, and is otherwise considered medical waste. It is, therefore, free of ethical concerns, unlike embryonic stem cells. Accordingly, hUC-MSCs represent a prospective source for MSCs to be exploited in cellbased therapy $[64,67,70,71]$. 


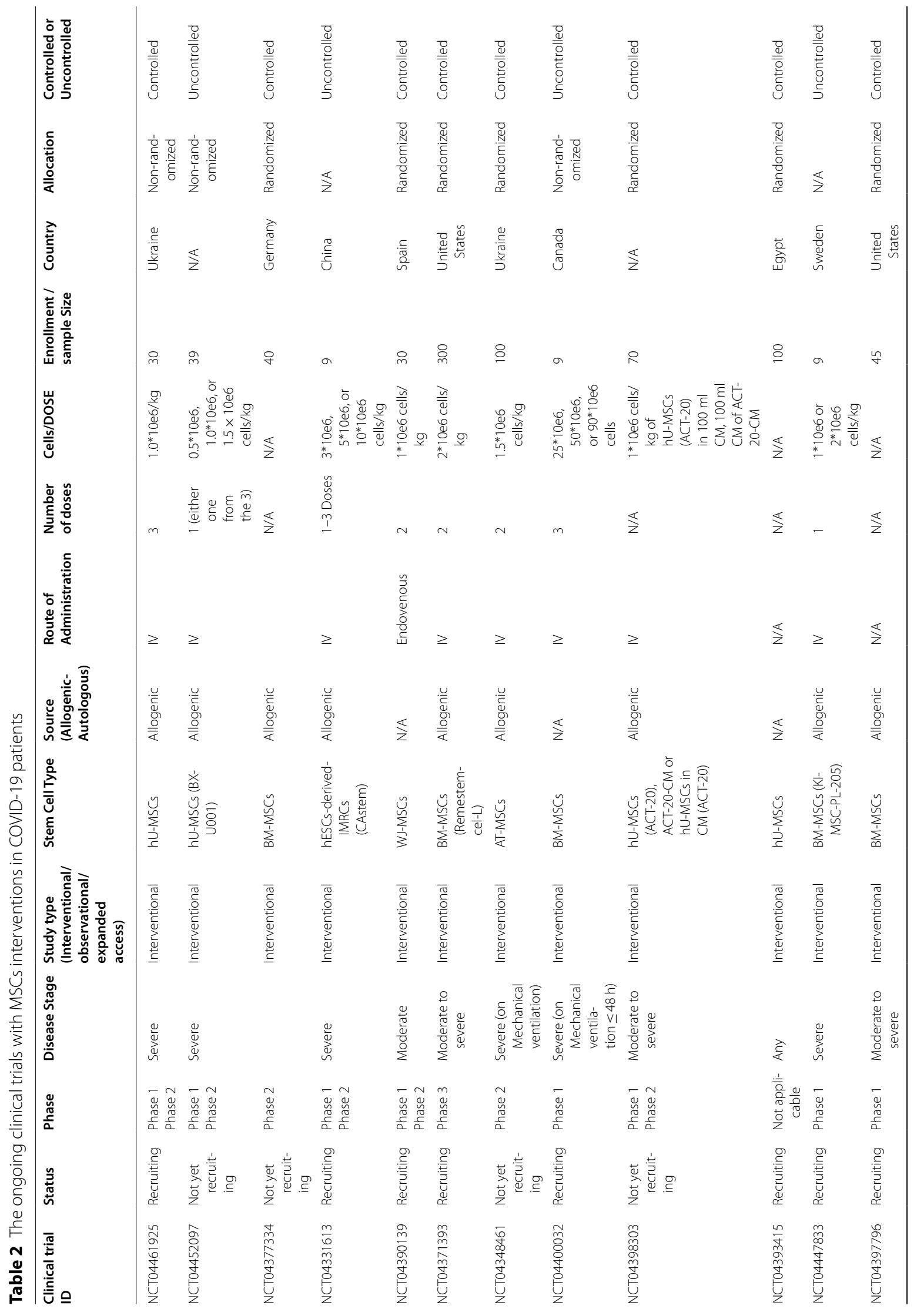




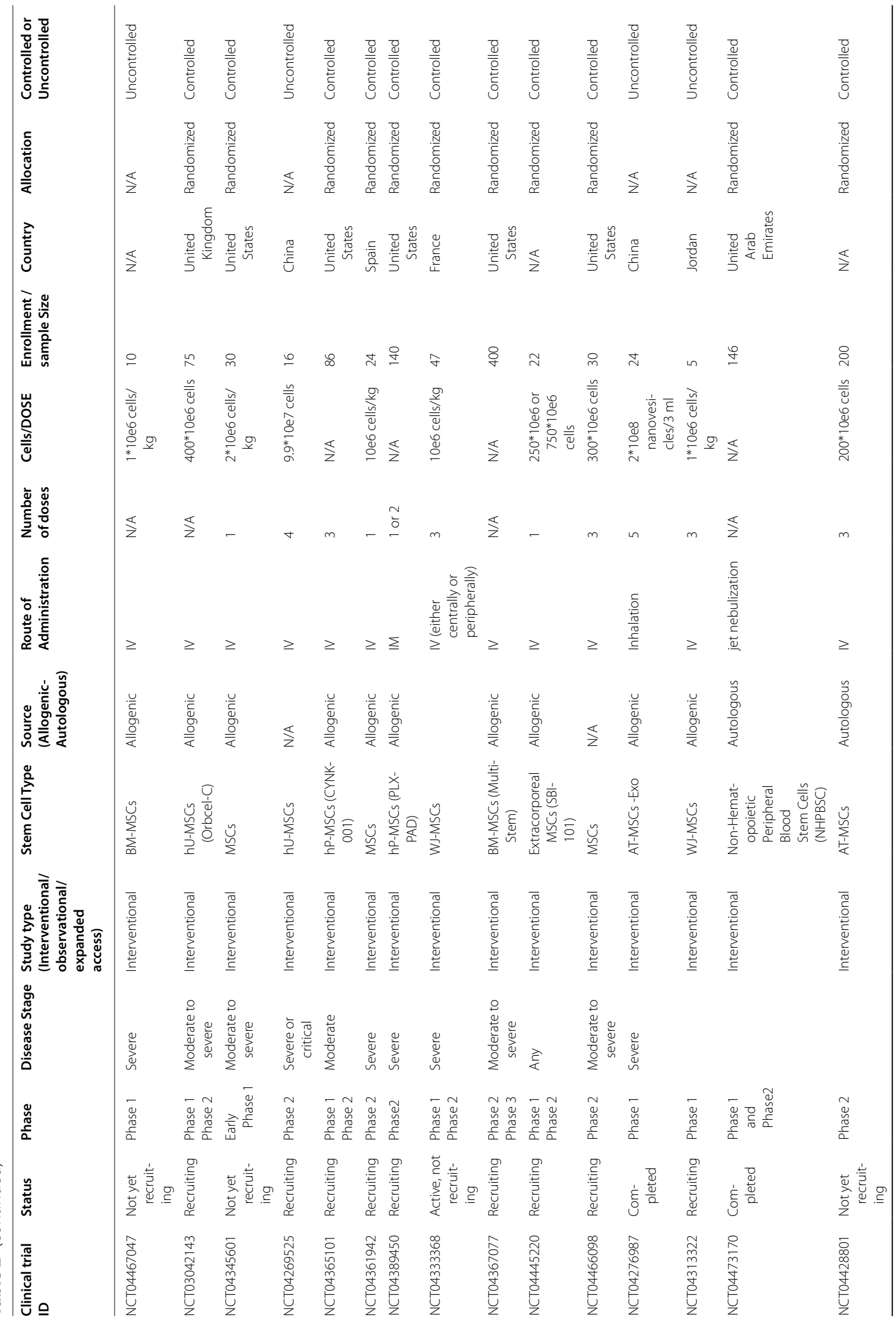




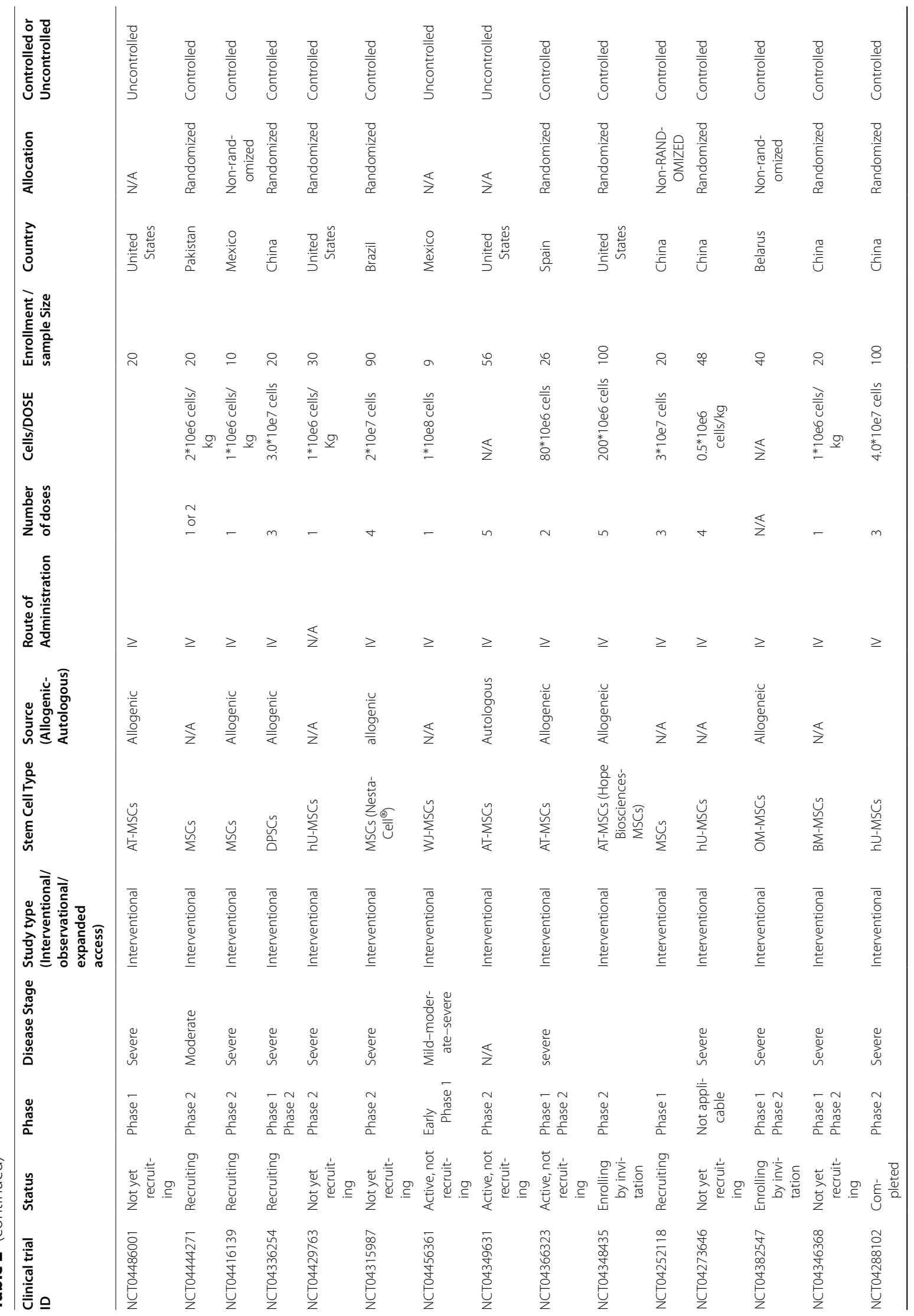




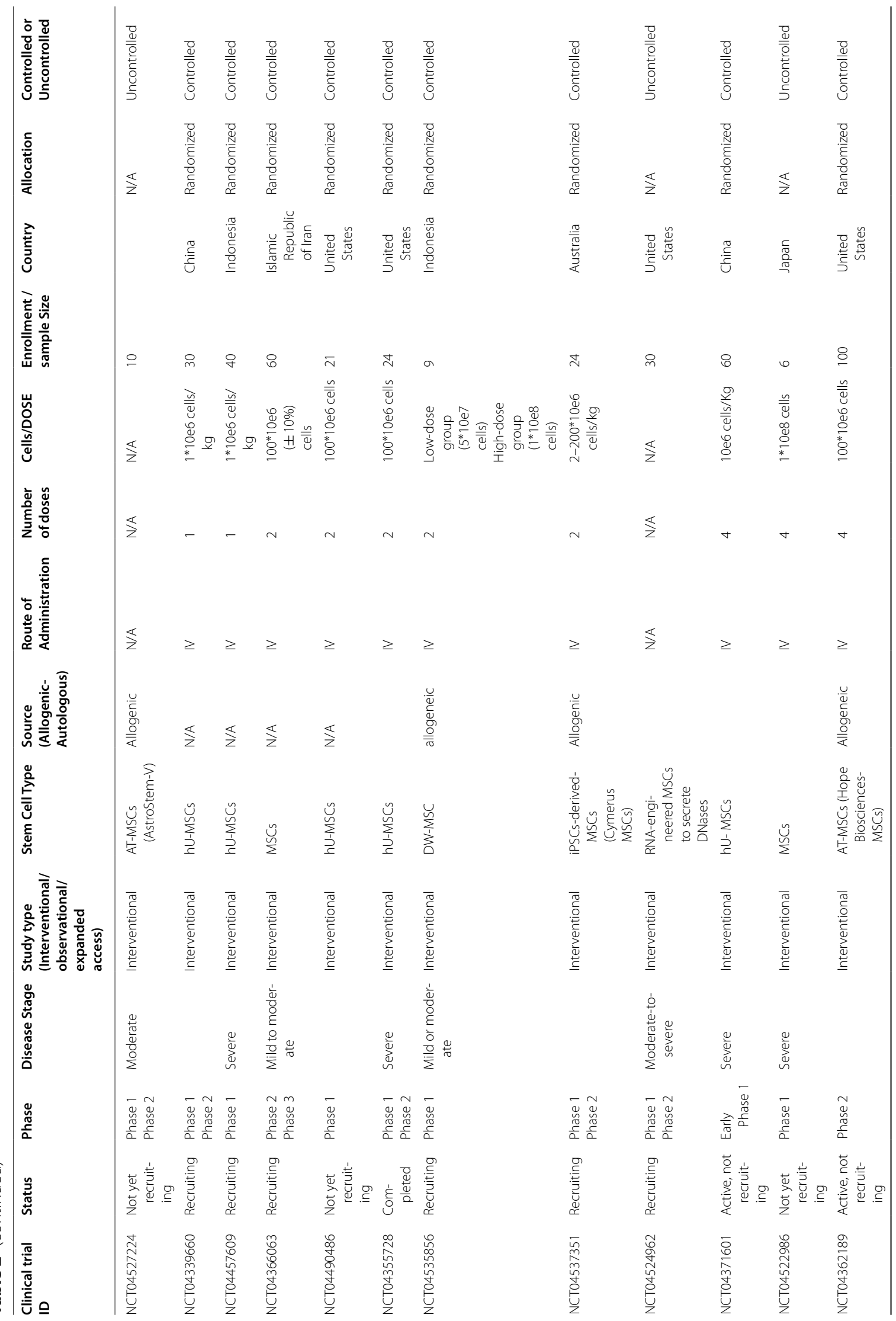




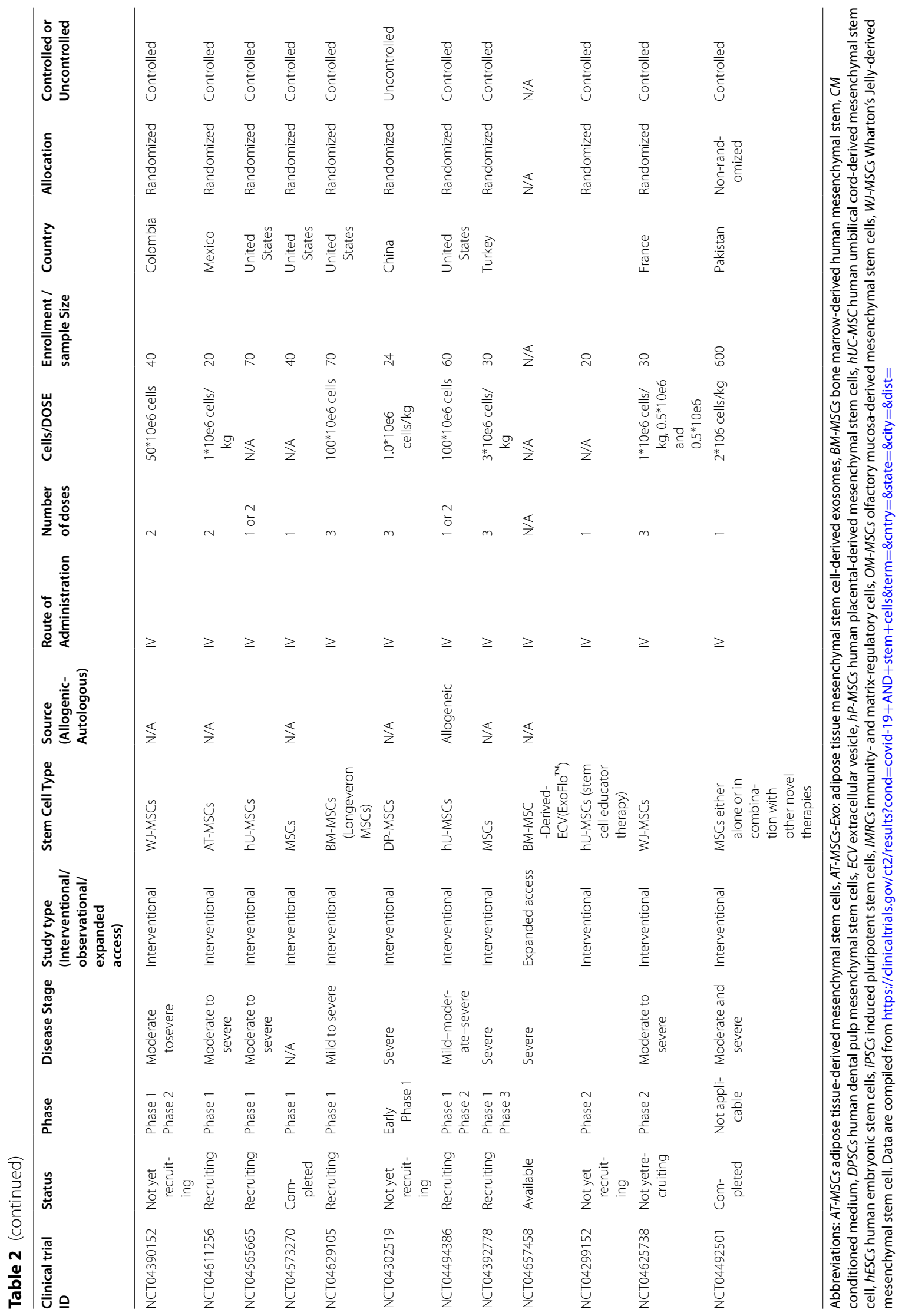


Several of the trials use MSCs due to their safety, efficacy, and potential for disease amelioration, boosting the immune system via immune cell reprogramming and relieving symptoms. Their differentiation ability and regenerative capacity also contribute to disease amelioration. MSCs migrate to damaged tissues, induce tissue repair, and exhibit an antiapoptotic effect without AEs.

\section{MSC-derived exosomes and COVID-19}

Despite the enormous success of MSCs in alleviating diseases, there are concerns regarding their safety, therapeutic efficacy, durability, and scalability $[57,58,72]$. Their therapeutic potential is primarily due to their secreted extracellular vesicles (EVs) [73]. EVs secreted from different cell sources are considered important messengers in intercellular communication as they transfer bioactive lipids, proteins, and nucleic acids. EVs include (1) exosomes, with a diameter of $40-150 \mathrm{~nm}$, which are released into the extracellular environment when multivesicular bodies fuse with the cell membrane, and (2) microvesicles, with a diameter of 150-1000 nm, developing from direct budding of the plasma membrane. MSCderived exosomes have several advantages: exosomes avoid MSCs' AEs, are nanoparticles with the ability to penetrate the blood-brain barrier, and avoid potential pulmonary embolism related to MSC transplantation. MSC-derived exosomes contain many bioactive molecules, such as lipids, proteins, mRNAs, long-noncoding RNAs, microRNAs, and mitochondrial DNA [74, 75]. MSC-derived exosomes exert anti-inflammatory and immunomodulatory effects in preclinical studies on myocardial infarction (MI), ischemia, cancer, lung injury, etc. [76, 77]. Exosomes exceed MSCs in sustainability and scalability as they are more stable than MSCs [25, 78]. However, their tumorigenic potential is debatable, as some studies support their tumor promotion potential, whereas others support their tumor inhibitory potential [79]. Preclinical and clinical studies have demonstrated the effects of exosomes in reducing cytokine storm complications, such as alveolar inflammation, edema, and epithelial tissue regeneration in inflammatory diseases, such as ARDS, asthma, COPD, and acute lung injury (ALI) $[25,80-86]$. Therefore, clinical trials may start to use MSC-derived exosomes to attenuate the cytokine storm in severe COVID-19.

There are some challenges in using exosomes. First, they modulate the immune response toward tolerance and homeostasis [87-90]. This response is desirable in non-infectious diseases, such as graft-versus-host disease, and are beneficial in infectious diseases, such as influenza [84, 91-93]. However, other viruses or bacteria might not respond in the same manner, because unconstrained replication may occur [87]. Second, MSCs are heterogeneous, and MSC-derived exosomes show heterogeneity. Variability is observed between different sources, such as the BM and $\mathrm{AD}$ tissue [94], or even in the same population or from the same source but different donors [95]. BM-MSC-derived EVs from different donors exhibit different cytokine contents, which affects their potency [87, 91]. AEs also can differ; for instance, AD-MSC-derived EVs show more thrombogenic markers and more significant thrombogenic potential than BMMSC-derived EVs [96]. This AE may pose a significant risk in COVID-19 as these patients are already at risk of thrombosis [97]. Therefore, an immortalized clonal MSC-derived EV line should be created to avoid potency variations and standardize the therapy [87].

A nonrandomized prospective study assessed the safety and efficacy of a BM-MSC-derived exosomal agent (ExoFlo) in 24 moderate-to-severe and severe COVID-19 patients. The patients were injected with $15 \mathrm{~mL}$ of ExoFlo and monitored for 14 days post-injection. No AEs were observed in the first $72 \mathrm{~h}$ post-injection. The majority of patients clinically recovered with improved oxygenation. Laboratory values of absolute neutrophil count, CRP, ferritin, and d-dimer decreased, while lymphocyte counts increased. This study demonstrated the potential safety and efficacy of BM-MSC-derived exosomes, which may be a promising therapeutic approach for COVID-19 [86].

However, the International Society for Cellular and Gene Therapies (ISCT) and the International Society for Extracellular Vesicles (ISEV) highlighted some issues with ExoFlo, such as insufficient data about Food and Drug Administration (FDA) approval, biological characteristics compared with other products, characterization, cell source evidence, and accurate dose (concentration $/ \mathrm{mL}$ ), and with the study, such as missing electrocardiogram (ECG) and pulse oximetry data. In addition, the ISCT and the ISEV questioned how events that occurred more than $72 \mathrm{~h}$ post-injection could certainly be unrelated to the exosomal agent [98]. Sengupta et al. [86] reported that ExoFlo is prepared by FDA-approved manufacturing facilities that meet current good manufacturing practice (cGMP) guidelines. They also provided light scatter and fluorescence data to confirm ExoFlo's characterization. Proteomic analysis revealed the presence of proteins with immunoregulatory, cell migration, angiogenesis, cell differentiation, and apoptosis regulation functions. In addition, the dose of ExoFlo was $15 \mathrm{~mL}$, with a concentration of $\sim 40$ million cells $/ \mathrm{mL}$. The authors also confirmed that the patients' vital signs, oxygen saturation, and ECG were regularly monitored post-injection for 14 days [99]. 


\section{Future approaches to enhancing MSC potency for COVID-19 treatment \\ MSC coating}

Despite the ability of MSCs to migrate to injury sites, the amount of engraftment is relatively low. For instance, only $1 \%$ of infused MSCs were found at the MI site in rats $4 \mathrm{~h}$ after infusion [100]. For MSCs to migrate to injured tissue, the tissue must first chemoattract MSCs from the blood circulation, which depends on several MSC surface markers, including L-selectin, CD44, CD24, CD49a-f, CD29, CD18, intercellular adhesion molecule (ICAM)-1, ICAM-2, and vascular cell adhesion molecule (VCAM)1 , and their interaction with specific target tissue markers [101].

Studies on cell surface modification of MSCs have shown promise in preclinical models [102]. Coating MSCs with sialyl Lewis X (SLeX), an essential mediator found on the leukocyte cell surface involved in leukocyte migration to inflamed tissues, is the first step in the migration process. Biotin-avidin technology can also be used to supply hMSCs with biotinylated lipid vesicles to facilitate linking to streptavidin-SLeX and increase migration toward the P-selectin substrate [103]. Similarly, in vivo, SLeX-engineered MSCs demonstrate enhanced migration to the inflamed endothelium compared with naive MSCs [104].

Another method of MSC coating is through antibodies targeted to antigens expressed in target sites. An in vitro study evaluated the migration of ICAM-1-MSCs to human umbilical vein endothelial cells (HUVECs) and detected enhanced binding. The binding intensified when HUVECs were pretreated with TNF- $\alpha$ to stimulate ICAM expression (105). An in vivo study used anti-VCAM-1 to coat MSCs before infusion in an experimental colitis and inflammatory bowel disease model. Increased migration of anti-VCAM-1-coated MSCs to injury sites was observed, with no AEs on MSC characteristics, morphology, or viability $[106,107]$. Therefore, MSC surface modifications can be a promising strategy for enhancing their therapeutic efficacy in COVID-19.

Finally, strategies using biodegradable/biocompatible MSC coatings have proven beneficial in MSC retention in cardiac tissue and could be modified to enhance their retention in lung tissue after IV administration $[98,108]$.

\section{Genetically modified MSCs}

Several studies have used genetically modified MSCs to enhance the expression of a specific therapeutic protein or deliver therapy aimed at a specific disease [109]. Genetic modification of MSCs can be performed via viral vector or nonviral delivery. In viral vector delivery, insertional mutagenesis, immunogenicity, and limited carrying capacity are the main concerns. These concerns are minimal in nonviral delivery, which includes liposomes, plasmids, and miniplasmids; however, this approach has low transfection ability and transitory transgene expression (110). Due to MSC tropism in cancer tissues, several preclinical studies have investigated the possibility of using genetically engineered MSCs to target diverse types of cancer [111-113]. In a murine xenograft melanoma model, tumor growth reduced following local transplantation of INF- $\beta$-transduced hMSCs [114]. Similarly, MSCs were engineered to express TNFrelated apoptosis-inducing ligand (TRAIL), which can induce apoptosis in cancer cells but not in healthy cells, and were proven efficacious in some preclinical studies $[115,116]$.

Genetically modified MSCs have also been tested in other diseases, such as Alzheimer's disease [117], neurodegenerative diseases [118], acute cardiovascular diseases [119], spinal cord injury [120], and systemic lupus erythematosus [121]. Lotfy et al. [36] reported that the immunomodulatory and neuroprotective effects of genetically modified MSCs can could be enhanced in vivo by genetically modulating important inflammatory targets, such as INF- $\beta$ and sphingosine kinase-1 (SPK1) $[122,123]$.

Several studies have assessed genetically modified MSCs in ARDS and radiation-induced lung injury. ACE2 has protective activity against severe acute lung injury [124]. ACE2-overexpressing hUC-MSCs played a more therapeutic anti-inflammatory role than unmodified MSCs in murine lung injury models [124, 125]. KGF plays a substantial role in lung epithelial cell repair and proliferation, and angiopoietin-1 sustains endothelial maturation and permeability [50, 126]. Both KGF-MSCs and angiopeotin-1-MSCs showed enhanced pulmonary vascular permeability and modulated pulmonary inflammation. There was a significant reduction in inflammatory mediators, including Cxcl2, IL-6, IL-1 $\beta$, IFN $\gamma$, and TNF- $\alpha$, in angiopoietin-1-MSCs compared with native MSCs. In another study, MSCs overexpressed decorin, a natural compound that attenuates fibrosis by inhibiting collagen-1, $\alpha$-smooth muscle actin ( $\alpha$-SMA), and TGF- $\beta 1$ [127].

More preclinical studies are required to implement genetic modification of MSCs to make them more potent therapeutic agents for COVID-19 treatment.

\section{MSCs and nanotechnology}

Nanotechnology can be exploited to improve the therapeutic efficacy and enhance the delivery of MSCs in COVID-19 in order to augment their therapeutic effects, ameliorate symptoms, and decrease mortality. Since the cytokine storm represents a significant risk for 
COVID-19 patients, there is an urgent need to inhibit it. Metcalfe et al. suggested that nanosynthetic stem cells (LIFNano) could inhibit and modulate the cytokine storm seen in COVID-19 [72]. LIFNano carries leukemia inhibitory factor (LIF) with 1000 times more potency than the soluble LIF released from MSCs. Quinton et al. demonstrated that endogenous LIF plays a crucial role in lung protection in acute lung injury [128]. LIFNano showed a therapeutic effect in a multiple sclerosis experimental animal model [129]. Therefore, LIFNano represents an alternative to MSC therapy because of its high volume and ability to inhibit the cytokine storm and repair damaged lung tissue [72].

Valizadeh et al. revealed that the nanocurcumin ameliorates the cytokine storm and decreases the expression and secretion of IL- 6 and IL- $1 \beta$ but not IL-18 and TNF- $\alpha$ in both serum and supernatant [130].

Nanocarriers have a wide range of applications and represent a delivery platform for drugs, vaccines, and cells because of their sustained release, selectivity, and specificity. Chitosan plays a substantial role in drug delivery into lung tissue in infectious diseases as it is a biodegradable, biocompatible, and safe polymer. It acts as a pulmonary particulate carrier for drugs because of its mucoadhesive effect and its ability to locate into the specific site, as well as its permeation [131]. Therefore, combining MSCs with chitosan hydrogel could enhance their therapeutic efficacy, permeation, adhesion, and targeting. Mehta et al. predicted that polysaccharide nanoparticles, nanotheranostics, and mesoporous silica nanoparticles would be promising targeted nanocarriers and drug delivery systems in COVID-19. Therefore, their combination with MSCs might pave the way for a new COVID19 treatment [132]. Some nanomaterials display antiviral efficacy, such as gold nanoparticles and heparan sulfate proteoglycan (HSPG) [133]. Therefore, combining MSCs with nanomaterials that exhibit antiviral activity might duplicate and enhance their therapeutic efficacy.

\section{MSC preconditioning}

MSCs can also be preconditioned with other compounds to synergize their effect or enhance the overall outcome for COVID-19 patients. For instance, MSCs can be preconditioned with vitamin $\mathrm{D}$, which acts as a strong immunomodulator [134]. Since MSCs might undergo apoptosis after transplantation, pretreatment with antioxidants might help protect them. Mohammadi et al. demonstrated that astaxanthin (ATX), a potent antioxidant, plays a protective and supportive role for AD-MSCs by overcoming oxidative stress; decreasing hydrogen peroxide, which induces cell apoptosis; and enhancing the expression of native cell antioxidants, such as heme oxygenase-1 (HO-1) and reduced nicotinamide adenine dinucleotide phosphate (NADPH) quinine oxidoreductase 1 (NQO1). Similar approaches could help protect MSCs and enhance their viability in harsh conditions and, hence, improve their therapeutic efficacy in COVID19 [135]. Interestingly, selenium is considered an antioxidant with a low toxicity profile and antiviral property. Therefore, selenium could be used, either in regular form or preferably in its nanoform as nanoselenium (nanoSe) [136], in combination with MSCs to ameliorate COVID19 symptoms.

\section{Conclusion}

SARS-CoV-2 emerged in Wuhan, China, and has become a life-threatening virus, causing the COVID-19 pandemic with significant morbidity and fatality rates. MSCs are the most commonly used stem cells in clinical trials, with validated safety, can migrate to sites of tissue injury, and can ameliorate the COVID-19-associated cytokine storm via their paracrine immunomodulatory effect. In fact, multiple studies are underway exploring the therapeutic efficacy of MSCs in patients with moderate-to-severe COVID-19. A cell-free approach, such as using MSCderived exosomes, promises similar therapeutic efficacy with fewer AEs. Future studies designed to enhance MSC therapy in COVID-19 can take advantage of advances in nanotechnology and cell surface and genetic modifications of MSCs to enhance their retention, survival, and immunomodulatory effects and to further improve their therapeutic efficacy in COVID-19.

\section{Abbreviations}

COVID-19: Coronavirus disease 2019; SARS-CoV-2: Severe acute respiratory syndrome coronavirus-2; MSC: Mesenchymal stem cell; ICU: Intensive care unit; TNF-a: Tumor necrosis factor alpha; IL: Interleukin; MIP: Macrophage inflammatory protein; MCP1: Monocyte chemoattractant protein 1; COPD: Chronic obstructive pulmonary disease; ARDS: Acute respiratory distress syndrome; mRNA: Messenger RNA; G-CSF: Granulocyte colony-stimulating factor; GM-CSF: Granulocyte-macrophage colony-stimulating factor; IL-1RA: Interleukin 1 receptor type 1; FGF-2: Fibroblast growth factor 2; VEGF-A: Vascular endothelial growth factor A; IFNy: Interferon gamma; IP10: IFNYinduced protein 10; PDGFB: Platelet-derived growth factor B; HLA: Human leukocyte antigen; IBD: Inflammatory bowel disease; T1D: Type 1 diabetes; PGE2: Prostaglandin E2; IDO: Indolamine 2,3-dioxygenase; hUC-MSC: Human umbilical cord tissue-derived MSC; BM: Bone marrow; KGF: Keratinocyte growth factor; MMP-9: Matrix metalloproteinase-9; HGF: Hepatocyte growth factor; $\mathrm{PaO}_{2}$ : Arterial partial pressure of oxygen; $\mathrm{FiO}_{2}$ : Fraction of $\mathrm{O}_{2}$ inspiration; RR: Respiratory rate; CT: Computed tomography; CRP: C-reactive protein; IV: Intravenous; AST: Aspartate transaminase; ALT: Alanine transaminase; EV: Extracellular vesicle; MHC: Major histocompatibility complex; ALI: Acute lung injury; ISCT: International society for cellular and gene therapies; ISEV: International society for extracellular vesicles; FDA: Food and Drug Administration; cGMP: Current good manufacturing practice; ECG: Electrocardiogram; MI: Myocardial infarction; ICAM: Intercellular adhesion molecule; VCAM: Vascular cell adhesion molecule; SLeX: Sialyl Lewis X; HUVEC: Human umbilical vein endothelial cell; SPK1: Sphingosine kinase-1; TGF- $\beta$ : Transforming growth factor beta; $a-S M A$ : a-Smooth muscle actin; LIF: Leukemia inhibitory factor; HSPG: Heparan sulfate proteoglycan; HO-1: Heme oxygenase-1; NADPH: Reduced nicotinamide adenine dinucleotide phosphate; NQO1: NADPH quinine oxidoreductase 
1; AT-MSCs: Adipose tissue-derived mesenchymal stem cells; AT-MSCs-Exo: Adipose tissue mesenchymal stem cell-derived exosomes; BM-MSCs: Bone marrow-derived human mesenchymal stem; CM: Conditioned medium; DPSCs: Human dental pulp mesenchymal stem cells; ECV: Extracellular vesicle; hP-MSCs: Human placental-derived mesenchymal stem cells; hUC-MSC: Human umbilical cord-derived mesenchymal stem cell; hESCs: Human embryonic stem cells; iPSCs: Induced pluripotent stem cells; IMRCs: Immunity- and matrix-regulatory cells; OM-MSCs: Olfactory mucosa-derived mesenchymal stem cells; WJ-MSCs: Wharton's Jelly-derived mesenchymal stem cell.

\section{Supplementary Information}

The online version contains supplementary material available at https://doi. org/10.1186/s13287-021-02542-z

Additional file 1. Properties of published studies of MSCs for COVID-19; including patient characteristics, MSCs characterization, and explanation of adverse events and serious adverse events.

Additional file 2. Detailed Excel sheet of the ongoing clinical trials with MSCs interventions in COVID-19 patients.

\section{Acknowledgements}

Authors would like to thank Dr. Bassma Abdelaziz, Mansoura University for her support. The authors would like to thank all healthcare workers in Egypt, US, and worldwide for their efforts against this pandemic.

\section{Authors' contributions}

The article was written by MA, NSB, AAF, AA, and AL. MA and NSB contributed equally to the acquisition of the data and manuscript preparation. $A A$ and $A L$ contributed equally to the study design, critical review the manuscript. All the authors read and approved the final form of the article.

\section{Funding}

Not applicable.

\section{Availability of data and materials}

All data presented in this review are totally available and present in the text.

\section{Code availability}

Not applicable.

\section{Declarations}

Ethics approval and consent to participate

Not applicable.

\section{Consent for publication}

Not applicable.

\section{Competing interests}

The authors declare that they have no competing interests.

\begin{abstract}
Author details
${ }^{1}$ Biotechnology and Life Sciences Department, Faculty of Postgraduate Studies for Advanced Sciences (PSAS), Beni-Suef University, Beni Suef 62511, Egypt. ${ }^{2}$ Materials Science and Nanotechnology Department, Faculty of Postgraduate Studies for Advanced Sciences (PSAS), Beni-Suef University, Beni Suef 62511, Egypt. ${ }^{3}$ Gill Heart Institute and Division of Cardiovascular Medicine, University of Kentucky and the Lexington VA Medical Center, Lexington, KY, USA. ${ }^{4} \mathrm{Col}-$ lege of Medicine, University of Kentucky, Lexington, KY 40506-0046, USA.
\end{abstract}

Received: 27 April 2021 Accepted: 3 Auqust 2021

Published online: 21 August 2021

\section{References}

1. https://www.cdc.gov/coronavirus/2019-ncov/symptoms-testing/ symptoms.html.

2. Ellul MA, Benjamin L, Singh B, Lant S, Michael BD, Easton A, et al. Neurological associations of COVID-19. Lancet Neurol. 2020;19(9):767-83.

3. Clerkin KJ, Fried JA, Raikhelkar J, Sayer G, Griffin JM, Masoumi A, et al. COVID-19 and cardiovascular disease. Circulation. 2020;141(20):1648-55.

4. Cui S, Chen S, Li X, Liu S, Wang F. Prevalence of venous thromboembolism in patients with severe novel coronavirus pneumonia. J Thromb Haemost JTH. 2020;18(6):1421-4.

5. Tiwari NR, Khatib KI, Dixit SB, Rathore PK, Melinkeri S, Ganapule A, et al. Anticoagulation in COVID_19: an update. J Crit Care Med (Targu Mures). 2020;6(4):217-23 (Epub 2020/11/18).

6. AlSubaie AM. Coagulopathies in novel coronavirus (SARS-CoV-2) pandemic: emerging evidence for hematologists. Saudi J Biol Sci. 2020.

7. Huang C, Wang Y, Li X, Ren L, Zhao J, Hu Y, et al. Clinical features of patients infected with 2019 novel coronavirus in Wuhan. China Lancet. 2020;395(10223):497-506.

8. Soy M, Keser G, Atagunduz P, Tabak F, Atagunduz I, Kayhan S. Cytokine storm in COVID-19: pathogenesis and overview of anti-inflammatory agents used in treatment. Clin Rheumatol. 2020;39(7):2085-94.

9. Singh TU, Parida S, Lingaraju MC, Kesavan M, Kumar D, Singh RK. Drug repurposing approach to fight COVID-19. Pharmacol Rep PR. 2020;72(6):1479-508.

10. Abdelgawad M, Allam S, Abdelmonaem Shaheen M, Ali Hussein M, Azmy Elkot H, Gaber A, et al. An overview of COVID-19 treatment: possible candidates based on drug repurposing and molecular docking. Can J Med. 2021;3(1):10-35.

11. Wang J, Peng Y, Xu H, Cui Z, Williams RO, 3rd. The COVID-19 vaccine race: challenges and opportunities in vaccine formulation. AAPS PharmSciTech. 2020;21(6):225

12. Shereen MA, Khan S, Kazmi A, Bashir N, Siddique R. COVID-19 infection: origin, transmission, and characteristics of human coronaviruses. J Adv Res. 2020;24:91-8.

13. Gentile P, Sterodimas A. Adipose-derived stromal stem cells (ASCs) as a new regenerative immediate therapy combating coronavirus (COVID19)-induced pneumonia. Expert Opin Biol Ther. 2020;20(7):711-6.

14. Parhizkar Roudsari P, Alavi-Moghadam S, Payab M, Sayahpour FA, Aghayan HR, Goodarzi P, et al. Auxiliary role of mesenchymal stem cells as regenerative medicine soldiers to attenuate inflammatory processes of severe acute respiratory infections caused by COVID-19. Cell Tissue Bank. 2020;21(3):405-25.

15. Cascella M, Rajnik M, Cuomo A, Dulebohn SC, Di Napoli R. Features, evaluation, and treatment of coronavirus. StatPearls. Treasure Island (FL) 2020.

16. Guo YR, Cao QD, Hong ZS, Tan YY, Chen SD, Jin HJ, et al. The origin, transmission and clinical therapies on coronavirus disease 2019 (COVID19) outbreak —an update on the status. Mil Med Res. 2020;7(1):11.

17. Rismanbaf A, Zarei S. Liver and kidney injuries in COVID-19 and their effects on drug therapy; a letter to editor. Arch Acad Emer Med. 2020;8(1):e17.

18. Rothan HA, Byrareddy SN. The epidemiology and pathogenesis of coronavirus disease (COVID-19) outbreak. J Autoimmun. 2020;109:102433.

19. Xu X, Han M, Li T, Sun W, Wang D, Fu B, et al. Effective treatment of severe COVID-19 patients with tocilizumab. Proc Natl Acad Sci USA. 2020;117(20):10970-5.

20. Fitzsimmons REB, Mazurek MS, Soos A, Simmons CA. Mesenchymal stromal/stem cells in regenerative medicine and tissue engineering. Stem Cells Int. 2018;2018:8031718.

21. Prockop DJ, Oh JY. Mesenchymal stem/stromal cells (MSCs): role as guardians of inflammation. Mol Ther J Am Soc Gene Ther. 2012;20(1):14-20.

22. Prockop DJ. The exciting prospects of new therapies with mesenchymal stromal cells. Cytotherapy. 2017;19(1):1-8.

23. Barry FP, Murphy JM. Mesenchymal stem cells: clinical applications and biological characterization. Int J Biochem Cell Biol. 2004;36(4):568-84.

24. Sheashaa H, Lotfy A, Elhusseini F, Aziz AA, Baiomy A, Awad S, et al. Protective effect of adipose-derived mesenchymal stem cells against acute kidney injury induced by ischemia-reperfusion in Sprague-Dawley rats. Exp Ther Med. 2016;11(5):1573-80. 
25. Alzahrani FA, Saadeldin IM, Ahmad A, Kumar D, Azhar El, Siddiqui AJ, et al. The potential use of mesenchymal stem cells and their derived exosomes as immunomodulatory agents for COVID-19 patients. Stem Cells Int. 2020;2020:8835986

26. Hass R, Kasper C, Bohm S, Jacobs R. Different populations and sources of human mesenchymal stem cells (MSC): A comparison of adult and neonatal tissue-derived MSC. Cell Commun Signal. 2011;9:12.

27. Lotfy A, El-Sherbiny YM, Cuthbert R, Jones E, Badawy A. Comparative study of biological characteristics of mesenchymal stem cells isolated from mouse bone marrow and peripheral blood. Biomed Rep. 2019;11(4):165-70.

28. Lotfy A, Salama M, Zahran F, Jones E, Badawy A, Sobh M. Characterization of mesenchymal stem cells derived from rat bone marrow and adipose tissue: a comparative study. Int J Stem Cells. 2014;7(2):135-42.

29. Cuthbert RJ, Jones E, Sanjurjo-Rodriguez C, Lotfy A, Ganguly P, Churchman SM, et al. Regulation of angiogenesis discriminates tissue resident MSCs from effective and defective osteogenic environments. J Clin Med. 2020;9(6):1628.

30. Dominici M, Le Blanc K, Mueller I, Slaper-Cortenbach I, Marini F, Krause $D$, et al. Minimal criteria for defining multipotent mesenchymal stromal cells. The International Society for Cellular Therapy position statement. Cytotherapy. 2006;8(4):315-7.

31. Kim HJ, Park JS. Usage of Human mesenchymal stem cells in cell-based therapy: advantages and disadvantages. Dev Reprod. 2017;21(1):1-10

32. Agadi S, Shetty AK. Concise review: prospects of bone marrow mononuclear cells and mesenchymal stem cells for treating status epilepticus and chronic epilepsy. Stem Cells. 2015;33(7):2093-103.

33. Freitag J, Bates D, Wickham J, Shah K, Huguenin L, Tenen A, et al. Adipose-derived mesenchymal stem cell therapy in the treatment of knee osteoarthritis: a randomized controlled trial. Regen Med. 2019;14(3):213-30.

34. Karussis D, Karageorgiou C, Vaknin-Dembinsky A, Gowda-Kurkalli B, Gomori JM, Kassis I, et al. Safety and immunological effects of mesenchymal stem cell transplantation in patients with multiple sclerosis and amyotrophic lateral sclerosis. Arch Neurol. 2010;67(10):1187-94.

35. Calonge M, Perez I, Galindo S, Nieto-Miguel T, Lopez-Paniagua M, Fernandez I, et al. A proof-of-concept clinical trial using mesenchymal stem cells for the treatment of corneal epithelial stem cell deficiency. Transl Res J Lab Clin Med. 2019;206:18-40.

36. Lotfy A, Ali NS, Abdelgawad M, Salama M. Mesenchymal stem cells as a treatment for multiple sclerosis: a focus on experimental animal studies. Rev Neurosci. 2020;31(2):161-79.

37. El-Gendy H, Hawass SE, Awad M, Mohsen MA, Amin M, Abdalla HA, et al. Comparative study between human mesenchymal stem cells and etanercept as immunomodulatory agents in rat model of rheumatoid arthritis. Immunol Res. 2020;68(5):255-68.

38. Le Blanc K, Mougiakakos D. Multipotent mesenchymal stromal cells and the innate immune system. Nat Rev Immunol. 2012;12(5):383-96.

39. Eljarrah A, Gergues M, Pobiarzyn PW, Sandiford OA, Rameshwar P. Therapeutic potential of mesenchymal stem cells in immune-mediated diseases. Adv Exp Med Biol. 2019;1201:93-108.

40. Gugliandolo A, Bramanti P, Mazzon E. Mesenchymal stem cells in multiple sclerosis: recent evidence from pre-clinical to clinical studies. Int Mol Sci. 2020;21(22):8662.

41. Gallo G, Tiesi V, Fulginiti S, De Paola G, Vescio G, Sammarco G. Mesenchymal stromal cell therapy in the management of perianal fistulas in Crohn's disease: an up-to-date review. Medicina (Kaunas). 2020;56(11):563.

42. Gregoire C, Lechanteur C, Briquet A, Baudoux E, Baron F, Louis E, et al. Review article: mesenchymal stromal cell therapy for inflammatory bowel diseases. Aliment Pharmacol Ther. 2017;45(2):205-21.

43. Radmanesh F, Mahmoudi M, Yazdanpanah E, Keyvani V, Kia N, Nikpoor $A R$, et al. The immunomodulatory effects of mesenchymal stromal cell-based therapy in human and animal models of systemic lupus erythematosus. IUBMB Life. 2020;72(11):2366-81.

44. Lotfy A, Elgamal A, Burdzinska A, Swelum AA, Soliman R, Hassan AA, et al. Stem cell therapies for autoimmune hepatitis. Stem Cell Res Ther. 2021;12(1):386.

45. Lin F, Ichim TE, Pingle S, Jones LD, Kesari S, Ashili S. Mesenchymal stem cells as living anti-inflammatory therapy for COVID-19 related acute respiratory distress syndrome. World J Stem Cells. 2020;12(10):1067-79.
46. Min H, Xu L, Parrott R, Overall CC, Lillich M, Rabjohns EM, et al. Mesenchymal stromal cells reprogram monocytes and macrophages with processing bodies. Stem Cells. 2020.

47. Walter J, Ware LB, Matthay MA. Mesenchymal stem cells: mechanisms of potential therapeutic benefit in ARDS and sepsis. Lancet Respir Med. 2014;2(12):1016-26.

48. Rojas M, Xu J, Woods CR, Mora AL, Spears W, Roman J, et al. Bone marrow-derived mesenchymal stem cells in repair of the injured lung. Am J Respir Cell Mol Biol. 2005;33(2):145-52.

49. Li Y, Xu J, Shi W, Chen C, Shao Y, Zhu L, et al. Mesenchymal stromal cell treatment prevents H9N2 avian influenza virus-induced acute lung injury in mice. Stem Cell Res Ther. 2016;7(1):159.

50. Mei SH, McCarter SD, Deng Y, Parker CH, Liles WC, Stewart DJ. Prevention of LPS-induced acute lung injury in mice by mesenchymal stem cells overexpressing angiopoietin 1. PLoS Med. 2007;4(9):e269.

51. Zheng G, Huang L, Tong H, Shu Q, Hu Y, Ge M, et al. Treatment of acute respiratory distress syndrome with allogeneic adipose-derived mesenchymal stem cells: a randomized, placebo-controlled pilot study. Respir Res. 2014;15:39.

52. Wilson JG, Liu KD, Zhuo H, Caballero L, McMillan M, Fang X, et al. Mesenchymal stem (stromal) cells for treatment of ARDS: a phase 1 clinical trial. Lancet Respir Med. 2015;3(1):24-32.

53. Simonson OE, Mougiakakos D, Heldring N, Bassi G, Johansson HJ, Dalen $M$, et al. In vivo effects of mesenchymal stromal cells in two patients with severe acute respiratory distress syndrome. Stem Cells Transl Med. 2016;5(6):845.

54. Shyamsundar M, McAuley DF, Ingram RJ, Gibson DS, O'Kane D, McKeown ST, et al. Keratinocyte growth factor promotes epithelial survival and resolution in a human model of lung injury. Am J Respir Crit Care Med. 2014;189(12):1520-9.

55. Yang Y, Chen QH, Liu AR, Xu XP, Han JB, Qiu HB. Synergism of MSCsecreted HGF and VEGF in stabilising endothelial barrier function upon lipopolysaccharide stimulation via the Rac1 pathway. Stem Cell Res Ther. 2015;6:250.

56. Xiao K, Hou F, Huang X, Li B, Qian ZR, Xie L. Mesenchymal stem cells: current clinical progress in ARDS and COVID-19. Stem Cell Res Ther. 2020;11(1):305.

57. Liang B, Chen J, Li T, Wu H, Yang W, Li Y, et al. Clinical remission of a critically ill COVID-19 patient treated by human umbilical cord mesenchymal stem cells: a case report. Medicine. 2020;99(31):e21429.

58. Leng Z, Zhu R, Hou W, Feng Y, Yang Y, Han Q, et al. Transplantation of ACE2(-) mesenchymal stem cells improves the outcome of patients with COVID-19 pneumonia. Aging Dis. 2020;11(2):216-28.

59. Shu L, Niu C, Li R, Huang T, Wang Y, Huang M, et al. Treatment of severe COVID-19 with human umbilical cord mesenchymal stem cells. Stem Cell Res Ther. 2020;1 1(1):361.

60. Meng F, Xu R, Wang S, Xu Z, Zhang C, Li Y, et al. Human umbilical cordderived mesenchymal stem cell therapy in patients with COVID-19: a phase 1 clinical trial. Signal Transduct Target Ther. 2020;5(1):172.

61. Lanzoni G, Linetsky E, Correa D, Messinger Cayetano S, Alvarez RA, Kouroupis D, et al. Umbilical cord mesenchymal stem cells for COVID19 acute respiratory distress syndrome: a double-blind, phase 1/2a, randomized controlled trial. Stem Cells Transl Med. 2021.

62. Feng Y, Huang J, Wu J, Xu Y, Chen B, Jiang L, et al. Safety and feasibility of umbilical cord mesenchymal stem cells in patients with COVID-19 pneumonia: a pilot study. Cell Prolif. 2020;53(12):e12947.

63. Clinical trials using mesenchymal stem cells in COVID-19 patients. https://clinicaltrials.gov/ct2/results?cond=covid-19+AND+stem+cells \&term $=\&$ cntry $=\&$ state $=\&$ city $=\&$ dist $=$.

64. Atluri S, Manchikanti L, Hirsch JA. Expanded umbilical cord mesenchymal stem cells (UC-MSCs) as a therapeutic strategy in managing critically III COVID-19 patients: the case for compassionate use. Pain Phys. 2020;23(2):E71-83.

65. Mason C, Dunnill P. Assessing the value of autologous and allogeneic cells for regenerative medicine. Regen Med. 2009;4(6):835-53.

66. McIntyre LA, Moher D, Fergusson DA, Sullivan KJ, Mei SH, Lalu M, et al. Efficacy of mesenchymal stromal cell therapy for acute lung injury in preclinical animal models: a systematic review. PLOS ONE. 2016;11(1):e0147170. 
67. Arutyunyan I, Elchaninov A, Makarov A, Fatkhudinov T. Umbilical cord as prospective source for mesenchymal stem cell-based therapy. Stem cells international. 2016;2016:6901286.

68. Weiss ML, Troyer DL. Stem cells in the umbilical cord. Stem Cell Rev. 2006;2(2):155-62.

69. Coulson-Thomas VJ, Gesteira TF, Hascall V, Kao W. Umbilical cord mesenchymal stem cells suppress host rejection: the role of the glycocalyx. J Biol Chem. 2014;289(34):23465-81.

70. Guo Z, Chen Y, Luo X, He X, Zhang Y, Wang J. Administration of umbilical cord mesenchymal stem cells in patients with severe COVID-19 pneumonia. Crit Care. 2020;24(1):420.

71. Wei F, Kong D, Li T, Li A, Tan Y, Fang J, et al. Efficacy and safety of umbilical cord mesenchymal stem cells for the treatment of patients with COVID-19. Clinics (Sao Paulo). 2021;76:e2604

72. Metcalfe SM. Mesenchymal stem cells and management of COVID-19 pneumonia. Med Drug Discov. 2020:5:100019.

73. Burke J, Kolhe R, Hunter M, Isales C, Hamrick M, Fulzele S. Stem cellderived exosomes: a potential alternative therapeutic agent in orthopaedics. Stem Cells Int. 2016;2016:5802529.

74. Yin K, Wang S, Zhao RC. Exosomes from mesenchymal stem/stromal cells: a new therapeutic paradigm. Biomark Res. 2019;7:8.

75. Cai J, Wu J, Wang J, Li Y, Hu X, Luo S, et al. Extracellular vesicles derived from different sources of mesenchymal stem cells: therapeutic effects and translational potential. Cell Biosci. 2020;10:69.

76. Schultz IC, Bertoni APS, Wink MR. Mesenchymal stem cell-derived extracellular vesicles carrying miRNA as a potential multi target therapy to COVID-19: an in silico analysis. Stem Cell Rev Rep. 2021.

77. Allan D, Tieu A, Lalu M, Burger D. Mesenchymal stromal cell-derived extracellular vesicles for regenerative therapy and immune modulation: progress and challenges toward clinical application. Stem Cells Transl Med. 2020;9(1):39-46.

78. Cha JM, Shin EK, Sung JH, Moon GJ, Kim EH, Cho YH, et al. Efficient scalable production of therapeutic microvesicles derived from human mesenchymal stem cells. Sci Rep. 2018;8(1):1171.

79. Zhao R, Chen X, Song H, Bie Q, Zhang B. Dual role of MSC-derived exosomes in tumor development. Stem Cells Int. 2020;2020:8844730.

80. Lee JH, Park J, Lee JW. Therapeutic use of mesenchymal stem cell-derived extracellular vesicles in acute lung injury. Transfusion. 2019;59(S1):876-83

81. Zhu YG, Feng XM, Abbott J, Fang XH, Hao Q, Monsel A, et al. Human mesenchymal stem cell microvesicles for treatment of Escherichia coli endotoxin-induced acute lung injury in mice. Stem Cells. 2014;32(1):116-25.

82. Tang XD, Shi L, Monsel A, Li XY, Zhu HL, Zhu YG, et al. Mesenchymal stem cell microvesicles attenuate acute lung injury in mice partly mediated by Ang-1 mRNA. Stem Cells. 2017;35(7):1849-59.

83. Morrison TJ, Jackson MV, Cunningham EK, Kissenpfennig A, McAuley DF, O'Kane CM, et al. Mesenchymal stromal cells modulate macrophages in clinically relevant lung injury models by extracellular vesicle mitochondrial transfer. Am J Respir Crit Care Med. 2017;196(10):1275-86.

84. Hao Q, Gudapati V, Monsel A, Park JH, Hu S, Kato H, et al. Mesenchymal stem cell-derived extracellular vesicles decrease lung injury in mice. J Immunol. 2019;203(7):1961-72.

85. Harrell CR, Miloradovic D, Sadikot R, Fellabaum C, Markovic BS, Acovic $A$, et al. Molecular and cellular mechanisms responsible for beneficial effects of mesenchymal stem cell-derived product "Exo-d-MAPPS" in attenuation of chronic airway inflammation. Anal Cell Pathol (Amst). 2020;2020:3153891.

86. Sengupta V, Sengupta S, Lazo A, Woods P, Nolan A, Bremer N. Exosomes derived from bone marrow mesenchymal stem cells as treatment for severe COVID-19. Stem Cells Dev. 2020;29(12):747-54.

87. Borger V, Weiss DJ, Anderson JD, Borras FE, Bussolati B, Carter DRF, et al. International Society for Extracellular Vesicles and International Society for Cell and Gene Therapy statement on extracellular vesicles from mesenchymal stromal cells and other cells: considerations for potential therapeutic agents to suppress coronavirus disease-19. Cytotherapy. 2020;22(9):482-5

88. Giebel B, Hermann DM. Identification of the right cell sources for the production of therapeutically active extracellular vesicles in ischemic stroke. Ann Transl Med. 2019;7(9):188.
89. Zhang B, Yeo RWY, Lai RC, Sim EWK, Chin KC, Lim SK. Mesenchymal stromal cell exosome-enhanced regulatory T-cell production through an antigen-presenting cell-mediated pathway. Cytotherapy. 2018;20(5):687-96.

90. Zhang B, Yin Y, Lai RC, Tan SS, Choo AB, Lim SK. Mesenchymal stem cells secrete immunologically active exosomes. Stem Cells Dev. 2014:23(11):1233-44.

91. Kordelas L, Rebmann V, Ludwig AK, Radtke S, Ruesing J, Doeppner TR, et al. MSC-derived exosomes: a novel tool to treat therapy-refractory graft-versus-host disease. Leukemia. 2014;28(4):970-3.

92. Khatri M, Richardson LA, Meulia T. Mesenchymal stem cell-derived extracellular vesicles attenuate influenza virus-induced acute lung injury in a pig model. Stem Cell Res Ther. 2018;9(1):17.

93. Monsel A, Zhu YG, Gennai S, Hao Q, Hu S, Rouby JJ, et al. Therapeutic effects of human mesenchymal stem cell-derived microvesicles in severe pneumonia in mice. Am J Respir Crit Care Med. 2015;192(3):324-36

94. El-Badawy A, Amer M, Abdelbaset R, Sherif SN, Abo-Elela M, Ghallab $\mathrm{YH}$, et al. Adipose stem cells display higher regenerative capacities and more adaptable electro-kinetic properties compared to bone marrowderived mesenchymal stromal cells. Sci Rep. 2016;6:37801.

95. Costa LA, Eiro N, Fraile M, Gonzalez LO, Saa J, Garcia-Portabella P, et al. Functional heterogeneity of mesenchymal stem cells from natural niches to culture conditions: implications for further clinical uses. Cell Mol Life Sci CMLS. 2021;78(2):447-67.

96. Chance TC, Rathbone CR, Kamucheka RM, Peltier GC, Cap AP, Bynum $\mathrm{A}$. The effects of cell type and culture condition on the procoagulant activity of human mesenchymal stromal cell-derived extracellular vesicles. J Trauma Acute Care Surg. 2019;87(1S Suppl 1):S74-82.

97. Price LC, McCabe C, Garfield B, Wort SJ. Thrombosis and COVID-19 pneumonia: the clot thickens! Eur Respir J 2020;56(1).

98. Lim SK, Giebel B, Weiss DJ, Witwer KW, Rohde E. Re: "Exosomes derived from bone marrow mesenchymal stem cells as treatment for severe COVID-19" by Sengupta et al. Stem Cells Dev. 2020;29(14):877-8.

99. Sengupta V, Sengupta S, Lazo A, Jr., Hicok KC, Moseley T. Response to Lim et al. re: "Exosomes Derived from Bone Marrow Mesenchymal Stem Cells as Treatment for Severe COVID-19". Stem Cells Dev. 2020;29(14):879-81.

100. Barbash IM, Chouraqui P, Baron J, Feinberg MS, Etzion S, Tessone A, et al. Systemic delivery of bone marrow-derived mesenchymal stem cells to the infarcted myocardium: feasibility, cell migration, and body distribution. Circulation. 2003:108(7):863-8.

101. Kavanagh DP, Robinson J, Kalia N. Mesenchymal stem cell priming: finetuning adhesion and function. Stem Cell Rev Rep. 2014;10(4):587-99.

102. Wu PJ, Peng H, Li C, Abdel-Latif A, Berron BJ. Adhesive stem cell coatings for enhanced retention in the heart tissue. ACS Appl Bio Mater. 2020;3(5):2930-9.

103. Sarkar D, Vemula PK, Zhao W, Gupta A, Karnik R, Karp JM. Engineered mesenchymal stem cells with self-assembled vesicles for systemic cell targeting. Biomaterials. 2010;31(19):5266-74

104. Sarkar D, Spencer JA, Phillips JA, Zhao W, Schafer S, Spelke DP, et al. Engineered cell homing. Blood. 2011;118(25):e184-91.

105. Ko IK, Kean TJ, Dennis JE. Targeting mesenchymal stem cells to activated endothelial cells. Biomaterials. 2009;30(22):3702-10.

106. Chen Q, LiY, Chen Z, Du H, Wan J. Anti-VCAM 1 antibody-coated mesenchymal stromal cells attenuate experimental colitis via immunomodulation. Med Sci Monit Int Med J Exp Clin Res. 2019;25:4457-68.

107. Ko IK, Kim BG, Awadallah A, Mikulan J, Lin P, Letterio JJ, et al. Targeting improves MSC treatment of inflammatory bowel disease. Mol Ther J Am Soc Gene Ther. 2010;18(7):1365-72.

108. Gottipati A, Chelvarajan L, Peng H, Kong R, Cahall CF, Li C, et al. Gelatin based polymer cell coating improves bone marrow-derived cell retention in the heart after myocardial infarction. Stem Cell Rev Rep. 2019:15(3):404-14.

109. Sage EK, Thakrar RM, Janes SM. Genetically modified mesenchymal stromal cells in cancer therapy. Cytotherapy. 2016:18(11):1435-45.

110. Varkouhi AK, Monteiro APT, Tsoporis JN, Mei SHJ, Stewart DJ, Dos Santos CC. Genetically modified mesenchymal stromal/stem cells: application in critical illness. Stem Cell Rev Rep. 2020;16(5):812-27.

111. Studeny M, Marini FC, Dembinski JL, Zompetta C, Cabreira-Hansen $\mathrm{M}$, Bekele BN, et al. Mesenchymal stem cells: potential precursors for 
tumor stroma and targeted-delivery vehicles for anticancer agents. $J$ Natl Cancer Inst. 2004;96(21):1593-603.

112. Alieva M, Bago JR, Aguilar E, Soler-Botija C, Vila OF, Molet J, et al. Glioblastoma therapy with cytotoxic mesenchymal stromal cells optimized by bioluminescence imaging of tumor and therapeutic cell response. PLOS ONE. 2012;7(4):e35148,

113. Zischek C, Niess H, Ischenko I, Conrad C, Huss R, Jauch KW, et al. Targeting tumor stroma using engineered mesenchymal stem cells reduces the growth of pancreatic carcinoma. Ann Surg. 2009:250(5):747-53.

114. Studeny M, Marini FC, Champlin RE, Zompetta C, Fidler IJ, Andreeff M. Bone marrow-derived mesenchymal stem cells as vehicles for interferon-beta delivery into tumors. Can Res. 2002;62(13):3603-8.

115. Lathrop MJ, Sage EK, Macura SL, Brooks EM, Cruz F, Bonenfant NR, et al Antitumor effects of TRAIL-expressing mesenchymal stromal cells in a mouse xenograft model of human mesothelioma. Cancer Gene Ther. 2015;22(1):44-54

116. Grisendi G, Bussolari R, Cafarelli L, Petak I, Rasini V, Veronesi E, et al. Adipose-derived mesenchymal stem cells as stable source of tumor necrosis factor-related apoptosis-inducing ligand delivery for cancer therapy. Can Res. 2010;70(9):3718-29.

117. Kang JM, Yeon BK, Cho SJ, Suh YH. Stem cell therapy for Alzheimer's disease: a review of recent clinical trials. J Alzheimer's Dis JAD. 2016;54(3):879-89.

118. Wyse RD, Dunbar GL, Rossignol J. Use of genetically modified mesenchymal stem cells to treat neurodegenerative diseases. Int J Mol Sci. 2014;15(2):1719-45

119. Griffin M, Greiser U, Barry F, O'Brien T, Ritter T. Genetically modified mesenchymal stem cells and their clinical potential in acute cardiovascular disease. Discov Med. 2010;9(46):219-23.

120. Kumagai G, Tsoulfas P, Toh S, McNiece I, Bramlett HM, Dietrich WD. Genetically modified mesenchymal stem cells (MSCs) promote axonal regeneration and prevent hypersensitivity after spinal cord injury. Exp Neurol. 2013;248:369-80.

121. Xu J, Chen J, Li W, Lian W, Huang J, Lai B, et al. Additive therapeutic effects of mesenchymal stem cells and IL-37 for systemic lupus erythematosus. J Am Soc Nephrol. 2020;31(1):54-65 (Epub 2019/10/13).

122. Marin-Banasco C, Benabdellah K, Melero-Jerez C, Oliver B, Pinto-Medel $\mathrm{MJ}$, Hurtado-Guerrero I, et al. Gene therapy with mesenchymal stem cells expressing IFN-ss ameliorates neuroinflammation in experimental models of multiple sclerosis. Br J Pharmacol. 2017;174(3):238-53 (Epub 2016/11/25)

123. Wang YL, Xue P, Xu CY, Wang Z, Liu XS, Hua LL, et al. SPK1-transfected UCMSC has better therapeutic activity than UCMSC in the treatment of experimental autoimmune encephalomyelitis model of Multiple sclerosis. Sci Rep. 2018;8(1):1756.

124. Li Y, Zeng Z, Cao Y, Liu Y, Ping F, Liang M, et al. Angiotensin-converting enzyme 2 prevents lipopolysaccharide-induced rat acute lung injury via suppressing the ERK $1 / 2$ and NF-kappaB signaling pathways. Sci Rep. 2016;6:27911.
125. Min F, Gao F, Li Q, Liu Z. Therapeutic effect of human umbilical cord mesenchymal stem cells modified by angiotensin-converting enzyme 2 gene on bleomycin-induced lung fibrosis injury. Mol Med Rep. 2015;11(4):2387-96.

126. Chen J, Li C, Gao X, Liang Z, Yu L, Li Y, et al. Keratinocyte growth factor gene delivery via mesenchymal stem cells protects against lipopolysaccharide-induced acute lung injury in mice. PLoS ONE. 2013;8(12):e83303.

127. Liu D, Kong F, Yuan Y, Seth P, Xu W, Wang H, et al. Decorin-modified umbilical cord mesenchymal stem cells (MSCs) attenuate radiationinduced lung injuries via regulating inflammation, fibrotic factors, and immune responses. Int J Radiat Oncol Biol Phys. 2018;101 (4):945-56.

128. Quinton LJ, Mizgerd JP, Hilliard KL, Jones MR, Kwon CY, Allen E. Leukemia inhibitory factor signaling is required for lung protection during pneumonia. J Immunol. 2012;188(12):6300-8.

129. Metcalfe SM, Strom TB, Williams A, Fahmy TM. Multiple sclerosis and the LIF/IL- 6 axis: use of nanotechnology to harness the tolerogenic and reparative properties of LIF. Nanobiomedicine. 2015;2:5.

130. Valizadeh H, Abdolmohammadi-Vahid S, Danshina S, Ziya Gencer M, Ammari A, Sadeghi A, et al. Nano-curcumin therapy, a promising method in modulating inflammatory cytokines in COVID-19 patients. Int Immunopharmacol. 2020;89(Pt B):107088.

131. Rasul RM, Tamilarasi Muniandy M, Zakaria Z, Shah K, Chee CF, Dabbagh $A$, et al. A review on chitosan and its development as pulmonary particulate anti-infective and anti-cancer drug carriers. Carbohydr Polym. 2020;250:116800.

132. Mehta M, Prasher P, Sharma M, Shastri MD, Khurana N, Vyas M, et al. Advanced drug delivery systems can assist in targeting coronavirus disease (COVID-19): a hypothesis. Med Hypoth. 2020;144:110254.

133. Tang Z, Zhang $X$, Shu Y, Guo M, Zhang H, Tao W. Insights from nanotechnology in COVID-19 treatment. Nano Today. 2021:36:101019.

134. Rastogi A, Bhansali A, Khare N, Suri V, Yaddanapudi N, Sachdeva N, et al. Short term, high-dose vitamin D supplementation for COVID19 disease: a randomised, placebo-controlled, study (SHADE study). Postgraduate Med J. 2020.

135. Mohammadi S, Barzegari A, Dehnad A, Barar J, Omidi Y. Astaxanthin protects mesenchymal stem cells from oxidative stress by direct scavenging of free radicals and modulation of cell signaling. Chem Biol Interact. 2021;333:109324.

136. He L, Zhao J, Wang L, Liu Q, Fan Y, Li B, et al. Using nano-selenium to combat Coronavirus Disease 2019 (COVID-19)? Nano Today. 2021;36:101037.

\section{Publisher's Note}

Springer Nature remains neutral with regard to jurisdictional claims in published maps and institutional affiliations.
Ready to submit your research? Choose BMC and benefit from:

- fast, convenient online submission

- thorough peer review by experienced researchers in your field

- rapid publication on acceptance

- support for research data, including large and complex data types

- gold Open Access which fosters wider collaboration and increased citations

- maximum visibility for your research: over $100 \mathrm{M}$ website views per year

At BMC, research is always in progress.

Learn more biomedcentral.com/submissions 